Trascender, Contabilidad y Gestión. Vol. 7, Núm. 19 (enero - abril del 2022).

Universidad de Sonora. Departamento de Contabilidad. México.

ISSN: 2448-6388. Reserva de Derechos 04-2015-04172070800-203.

\title{
El estado de valor añadido. Evolución histórica, relevancia y limitaciones
}

\author{
The value added statement. Historical evolution, relevance and limitations
}

José Juan Déniz Mayor ${ }^{1}$; Luis Miguel Arteaga Arzola ${ }^{2}$; Casiano Manrique de Lara Peñate ${ }^{3}$

Recibido: 14 de agosto de 2021.

Aceptado: 4 de septiembre de 2021.

DOI: https://doi.org/10.36791/tcg.v7i19.135

JEL: J30. General.

M14. Corporate Culture - Diversity - Social responsibility.

M41. Accounting.

\section{Resumen}

Desde los primeros modelos formales de los años setenta hasta sus más recientes versiones, el Estado de valor añadido (o en su caso, el Estado de rentas generadas y distribuidas) ha estado asociado, en cierta medida, a la noción de responsabilidad corporativa. Al mostrar cómo se genera la renta empresarial y cómo se distribuye entre los grupos de interés relevantes, se ha pretendido presentar la imagen de la organización como una coalición de intereses, una "gran familia”. Tras una época de declive, ahora comienza a gozar de una nueva vida gracias a la Global Reporting Initiative y las normas legales de los organismos oficiales de la Unión Europea. No obstante, parece oportuno volver a analizar cuáles fueron los motivos de su auge inicial y su aparente abandono al objeto de evaluar si realmente este tipo

\footnotetext{
${ }^{1}$ José Juan Déniz Mayor. Doctor en Ciencias Económicas y Empresariales. Profesor Titular de Universidad. Departamento de Economía Financiera y Contabilidad, Campus de Tafira, Universidad de Las Palmas de Gran Canaria, Las Palmas de Gran Canaria, España. Correo: josejuan.deniz@ulpgc.es. ORCID: 0000-0002-6960-1512.

${ }^{2}$ Luis Miguel Arteaga Arzola. Grado en Administración y Dirección de Empresas. Master en Contabilidad, Auditoría y Fiscalidad Empresarial. Investigador independiente. Correo: luismiarteaga@gmail.com

${ }^{3}$ Casiano Manrique de Lara Peñate. Doctor en Economía. Profesor Contratado Departamento de Análisis Económico Aplicado, Campus de Tafira, Universidad de Las Palmas de Gran Canaria, Las Palmas de Gran Canaria, España. Correo: casiano.manrique@ulpgc.es. ORCID: 00000003-0809-7823.
} 
de informes es necesario hoy en día, para qué y para quién.

Palabras clave: contabilidad, estado de valor añadido, grupos de interés.

\section{Abstract}

Since the first formal models in the seventies to its most recent versions, the value added statement (or in its case, the statement of income generated and distributed) has been associated, to some extent, with the notion of corporate responsibility. By displaying how business income is generated and how it is distributed among the relevant stakeholders, it has been tried to present the image of the organization as a coalition of interests, a "big family". After a period of decline, it seems to enjoy a new life thanks to the Global Reporting Initiative and legal rules from official bodies of the European Union. However, it seems appropriate to re-analyze what were the reasons for its initial boom and its later apparent forgetting in order to assess whether this kind of report is really necessary today, for what and for whom.

Keywords: accounting, stakeholders, value added statement.

\section{Introducción}

Tradicionalmente el estudio y análisis del valor añadido bajo la perspectiva de la Contabilidad Financiera se ha asociado a su cálculo como un componente de los primeros escalones de la generación del resultado de explotación de la entidad.

Bajo tal perspectiva, esta magnitud ha sido definida como la diferencia entre el valor de la producción y venta de bienes y prestaciones de servicios que constituyen la(s) actividad(es) principal(es), y el importe de los bienes y servicios consumidos como insumos en el proceso productivo (también denominados consumos intermedios) (Gallizo, 1990, p. 63, Carrasco, 1999, p. 30, Reglamento (UE) 549/2013, en adelante SEC 2010, párr. 1.11). En sentido amplio, el valor añadido muestra la importancia económica de la empresa dentro del conjunto de la producción nacional, ya que la suma del valor añadido bruto a precios de mercado de todas las compañías de un país es igual a su producto interior bruto (PIB) siendo, además, y como señalan Gonzalo y Pérez (2017):

la variable que mejor liga la contabilidad empresarial con la contabilidad de la renta nacional [...] puede que algunos usuarios especiales, como por ejemplo las autoridades públicas, encontraran muy útil ligar las ayudas y subsidios a la generación de valor añadido, por equivaler a la creación de rentas (p. 35).

Esta idea hizo que la Contabilidad Nacional fuese el campo donde se comenzase a dar uso a la noción de valor añadido en respuesta a la necesidad de calcular la capacidad de producción de un país a nivel macroeconómico. La renta de la nación afecta no solo a sus ciudadanos, debido al estrecho vínculo entre esta magnitud económica y el bienestar colectivo, sino también al papel que dicho territorio jugará dentro de la economía mundial. 
En el ámbito empresarial, el cálculo y presentación de los datos relativos al valor añadido generado en el seno de las unidades económicas de negocio ha sido posible gracias al Estado de valor añadido ${ }^{1}$ (en adelante, EVA) y su versión ampliada, el Estado de rentas generadas y distribuidas (en adelante ERGD). El EVA muestra la riqueza generada y distribuida entre los distintos agentes que han contribuido a su creación, presentando el excedente de la empresa no como rendimiento de los accionistas de la misma, sino como el resultante del esfuerzo colectivo de los partícipes de la compañía (Larrinaga, 2001, p. 55). Alves (2015) lo define como:

la manera más simple y más inmediata de poner el beneficio en la perspectiva correcta de cara al conjunto de la empresa como un esfuerzo colectivo por el capital, la gestión y los empleados, reflejando cómo se ha utilizado el valor añadido para retribuir a los que contribuyen a su creación (p. 210).

Este estado ha representado una oportunidad para las empresas de mostrar de manera transparente los datos incluidos en la cuenta de pérdidas y ganancias desde una perspectiva multipartícipe, considerándose una aportación de la Contabilidad Financiera al fomento de la responsabilidad social corporativa (RSC) y la sostenibilidad (Azcárate y Fernández, 2013, Maji, 2016).

Si bien entre los años setenta y ochenta el EVA/ERGD gozó de relevancia entre las empresas europeas, incluyendo las españolas, su auge y declive se habría producido no solo debido a una determinada configuración social y política que ejemplifica la naturaleza social e institucional de la Contabilidad, sino también a la propia evolución de los estados contables convencionales.

Obviando los importantes desarrollos acaecidos en otras áreas geográficas, como por ejemplo Japón (Bao y Bao, 1998), Brasil (Veras et al. 2015), o Sudáfrica (Stainbank, 2009), en Europa cabe encontrar los primeros antecedentes del EVA/ERGD en el Reino Unido, aunque destacan los casos de la República Federal de Alemania (hoy Alemania) y Francia. Según la síntesis realizada por Dierkes (1979, p. 87), entre los factores que contribuyeron a su difusión en estos entornos se reseña el creciente volumen de publicaciones que alertaban de los riesgos ambientales de la actividad industrial, las movilizaciones ciudadanas relacionadas con la localización de las fábricas y el debate sobre la energía nuclear, así como el gran peso de los sindicatos. No obstante, diversos factores, como su aparente escasa utilidad práctica, la emergencia del neoliberalismo y el fin de la Guerra Fría o, probablemente, la existencia de formas alternativas de obtener los datos requeridos, abocarían al declive de este tipo de informes.

Posteriormente, y coincidiendo con la creciente importancia de las políticas de responsabilidad social empresarial, se ha observado una aparente revitalización del EVA/ERGD, con propuestas como el Estado de valor económico directo generado y distribuido de la Global Reporting Initiative (GRI) (2014, 2016), o el Estado de cash flow social. Es factible que esté jugando a su favor el hecho de que, al basarse en datos contables, supuestamente auditados, sea más fácil de formular e interpretar un informe de estas características, si se compara con la información no financiera, basada en el uso de métricas no monetarias y con un elevado componente cualitativo.

\footnotetext{
${ }^{1}$ En el presente trabajo se ha utilizado la denominación estándar en España, equivalente a la de “Estado de valor agregado” en otros entornos geográficos.
} 
En el presente trabajo se pretende dar respuesta a la cuestión de si dicho estado contable es relevante para la toma de decisiones de los grupos de interés, en especial los trabajadores. Así, por una parte, se analizará por qué desde los puntos de vista institucional y empresarial ha existido cierta reticencia a difundir dicho estado contable, en un contexto de creciente presión social para que las compañías rindan cuentas de su gestión e informen acerca de cómo distribuyen entre los diferentes agentes sociales las rentas generadas con su actividad. Por otro lado, se valorará la practicidad de los métodos de cálculo de rentas generadas y distribuidas como medio para medir la importancia relativa de los grupos de interés en la gestión corporativa. Para ello, se partirá de tres casos relativos al sector de la automoción, la construcción y el alojamiento hotelero en España, a través de los cuales se mostrará e interpretará la evolución del reparto de las rentas generadas entre los principales grupos de interés (trabajadores, prestamistas, gobierno, accionistas) y la propia empresa, desde el inicio de la crisis financiera de 2008 hasta 2019.

Para ello, en la siguiente sección se reflexionará sobre las causas que posibilitaron el auge de los EVA/ERGD en los años 70 y su posterior declive en la década de los noventa, junto con una reseña del caso español. En el apartado tercero se abordarán los aspectos metodológicos relativos a la selección de los componentes básicos de un EVA/ERGD y el consiguiente cálculo del valor añadido/renta generada. En la sección cuarta se exponen los ejemplos propuestos, previa descripción del proceso de selección de la muestra, la metodología de análisis y las principales limitaciones. El trabajo finaliza con las principales conclusiones alcanzadas. Además, se incluye dos apéndices, uno con los datos agregados que sirvieron de base para presentar los casos propuestos, y otro en el que se analiza el contenido de determinadas partidas del EVA/ERGD.

\section{Auge y caída del estado de valor añadido. Buscando una explicación de su aparente declive}

El EVA (o su versión ampliada el ERGD) gozó durante una época de un especial predicamento entre los grupos de interés relacionados con la empresa. Sin embargo y con el paso del tiempo, determinados factores, tanto políticos y económicos, como puramente instrumentales, acabaron contribuyendo a su caída en la irrelevancia.

Los primeros trabajos cabe encontrarlos en los años veinte y treinta gracias a Nicklish (1920) y su noción de "Wertschöpfung” (valor añadido). De acuerdo con dicho autor, la empresa debía ser vista como una comunidad y al mismo tiempo una "gran familia" integrada por gerentes y trabajadores (Hernández Estévez, 2011, p. 41), donde los salarios son considerados una distribución del resultado junto con los dividendos, antes que el pago de un gasto incurrido ${ }^{1}$.

En un primer momento, las ventajas atribuidas al EVA fueron expuestas desde la esfera académica. Así, en el trabajo ya clásico de Morley (1979, pp. 620-621) se observaba que este documento ofrecía una perspectiva más amplia sobre el desempeño corporativo que el beneficio en aras de alentar una actitud más cooperativa entre los grupos de interés, en especial por parte de los

\footnotetext{
${ }^{1}$ Es factible apuntar que esta noción de la "gran familia” fuese propuesta como una vía alternativa superadora de la lucha de clases y la conflictividad social que estaba experimentando la República de Weimar. Nicklish acabaría apoyando al NSDAP.
}

Déniz Mayor, J. J., Arteaga Arzola, L. M., y Manrique de Lara Peñate, $\mathrm{C}$. 
trabajadores, porque facilitaba la implantación de esquemas de incentivos basados en el valor añadido ${ }^{1}$; pero también porque podría ayudar a combatir la creencia de que existe explotación en el trabajo, al mostrar cómo se repartían las rentas entre los distintos colectivos, en un momento en el que el conflicto entre trabajo y capital era más que evidente. Además, y a su juicio, mostrar la participación del gobierno en el valor añadido generado facilitaría una evaluación del trato imparcial en materia de tributación; mientras que la propia noción de valor añadido, al mostrar el peso de la contribución de la empresa individual al ingreso nacional, podría desempeñar un papel en la gestión de la economía. También aportaría datos acerca de los recursos que pueden ser destinados al mantenimiento y la expansión de la inversión dirigiendo la atención a la política de gestión en esta área. Por último, se argüía que el valor añadido es una medida mejor para definir el tamaño de la empresa, que el total de activos, la cifra de negocios o el número de trabajadores ${ }^{2}$.

Por otra parte, y desde una perspectiva organizativa, gracias al EVA se visibiliza la noción de capital humano o intelectual como contribuyente al proceso de creación y acumulación de valor en el seno de la empresa, junto con el capital financiero (Bagieńska, 2016, p. 13). Al igual que los socios y prestamistas son retribuidos por sus aportaciones de fondos a la compañía, los trabajadores, en tanto que colaboran de forma consciente, deliberada y directa en el logro de los objetivos de la empresa, deberían ser objeto de consideración en los mismos términos en pie de igualdad, y no ser percibidos como un mero "recurso" más ${ }^{3}$, generador de costes que deban ser minimizados en aras de un bien superior como es la supervivencia a largo plazo de la empresa. De esta forma, y desde la teoría de los stakeholders, la actividad de la empresa no debería ser percibida únicamente como un mecanismo de generación de beneficios, sino como una herramienta para la creación y distribución de renta entre los grupos de interés.

Será durante el mandato del gobierno laborista de Harold Wilson (1974-1979) y el marco de la redefinición de los equilibrios de poder entre empresarios y sindicatos, cuando el Accounting Standards Steering Committee (ASSC) comisione en 1974 a un grupo de trabajo para reexaminar el alcance y fines de los informes financieros publicados, considerando la responsabilidad de la empresa ante la sociedad e identificando los grupos para los cuales fuese necesario preparar informes anuales adaptados a sus intereses.

Un año más tarde, ve la luz The Corporate Report que incluye entre sus conclusiones la ausencia de rendición de cuentas por parte de la empresa hacia sus trabajadores y la recomendación, entre otras, de publicar un estado que mostrase cómo los beneficios de los esfuerzos de una empresa se distribuyen entre los empleados, los proveedores de capital propio y ajeno, el

\footnotetext{
${ }^{1}$ Estos sistemas, que fueron objeto de una campaña de fomento en el Reino Unido, relacionaban los incrementos individuales de salarios con una ratio básica de productividad, de manera que, al fijar un precio para cada componente producido por un trabajador cualquiera, en término de tiempo estándar, se obtuviese la ratio aplicable a su sueldo. En este caso, el valor añadido funcionaba como un medio para medir el rendimiento y fijar la retribución de los distintos factores (Hernández, 1997, p. 111).

${ }^{2}$ El razonamiento es que la cifra de ventas no tiene en cuenta el coste de los bienes y servicios adquiridos, el tamaño del activo favorece a las empresas intensivas en capital físico, mientras que el número de trabajadores favorece a las empresas intensivas en mano de obra.

${ }^{3}$ Si realmente las palabras contribuyen a enmarcar la realidad, quizás no haya un concepto menos acertado en el marco de las relaciones laborales que el de "Dirección de recursos humanos".
}

Déniz Mayor, J. J., Arteaga Arzola, L. M., y Manrique de Lara Peñate, C. 
Estado y la reinversión en el propio negocio (Accounting Standards Steering Committee, 1975, p.49). Es a partir de la publicación de The Corporate Report cuando realmente se produce una creciente inclusión de este tipo de documentos en los informes anuales de las empresas británicas. Así, más allá del mero cálculo de una simple magnitud contable, el EVA comienza a ser percibido como una herramienta de comunicación, con una clara función legitimadora ante trabajadores y sindicatos (Burchell et al., 1985, van Staden, 2003, Cahan y van Staden, 2009).

La mayoría de las instituciones expertas en la materia fueron favorables a las conclusiones de The Corporate Report, aunque con cierta moderación, pues existía un escaso soporte empírico acerca de su utilidad práctica. Tal es así que coincidiendo, aunque no necesariamente por tal motivo, como sí sostienen Burchell et al. (1985), con la llegada de un nuevo gabinete conservador, liderado por Margaret Tatcher, y la emergencia de la ideología neoliberal se produce su declive en el Reino Unido ${ }^{1}$.

En Alemania, los primeros informes sobre valor añadido fueron presentados por grandes empresas industriales a partir de la década de los 70, existiendo una línea de continuidad hasta el presente. Este interés por los EVA/ERGD fue el resultado de la iniciativa política de los gobiernos socialdemócratas de la época, con Willy Brandt y Helmut Schmidt al frente, para fomentar el diálogo social en el marco de la cogestión empresarial, motivado además por un creciente reconocimiento del coste social del desarrollo económico y un cambio en su percepción entre la élite intelectual y política (Dierkes, 1979, p. 87). Así, junto con las británicas, se puede hablar de las empresas alemanas como pioneras en Europa en la formulación de información social, orientación que se ha mantenido hasta el presente, siendo una muestra el EVA/ERGD del Grupo Volkswagen (Tabla 1).

\section{Tabla 1}

Valor añadido generado por el grupo Volkswagen

\begin{tabular}{|c|c|c|}
\hline Source of funds in $€$ million 20172016 & 2017 & 2016 \\
\hline Sales revenue & 230,682 & 217,267 \\
\hline Other income & 18,912 & 17,907 \\
\hline Cost of materials & $-151,449$ & $-140,307$ \\
\hline Depreciation and amortization & $-22,165$ & $-20,924$ \\
\hline Other upfront expenditures & $-17,615$ & $-23,990$ \\
\hline Value added & 58,364 & 49,953 \\
\hline
\end{tabular}

${ }^{1}$ Nótese que el posterior retorno del laborismo al gobierno en 1997 no se tradujo en una recuperación de dicho estado contable. 


\section{Tabla 1}

Continuación...

\begin{tabular}{|c|c|c|c|c|}
\hline Appropriation of funds in $€$ million & 2017 & $\%$ & 2016 & $\%$ \\
\hline $\begin{array}{l}\text { to Volkswagen AG shareholders (dividend, } 2017 \\
\text { dividend proposal) }\end{array}$ & 1,967 & 3.4 & 1,015 & 2.0 \\
\hline to employees (wages, salaries, benefits) & 38,950 & 66.7 & 37,017 & 74.1 \\
\hline to the state (taxes, duties) & 3,433 & 5.9 & 3,486 & 7.0 \\
\hline to creditors (interest expense) & 4,344 & 7.4 & 4,070 & 8.1 \\
\hline to the Company (reserves) & 9,671 & 16.6 & 4,365 & 8.7 \\
\hline Value added & 58,364 & $\mathbf{1 0 0 . 0}$ & 49,953 & $\mathbf{1 0 0 . 0}$ \\
\hline
\end{tabular}

Fuente: Value added statement. Annual report 2017 (Volkswagen Group, 2018, p. 126).

En Francia la noción de valor añadido figuraba en el Plan Comptable Général de 1982 (Conseil National de la Comptabilité, 1982/1992), que recoge dicha magnitud como uno de los saldos intermedios de gestión cuyo producto final es el resultado del ejercicio, sin hacer referencia a su posible reparto o distribución entre los diferentes grupos de interés. Dicha referencia se conserva en el vigente Plan (Autorité des Normes Comptables, 2014) en el Cuadro de saldos intermedios de gestión, como herramienta de apoyo a la formulación de la Contabilidad Nacional ${ }^{1}$.

Finalmente, en España y a la vista de la necesidad de incorporar al ordenamiento interno la Cuarta Directiva del Consejo de la CEE (1978) que regulaba la información financiera de las sociedades, se presenta en 1985 el borrador de un Plan General de Contabilidad
Revisado, como sustituto del hasta entonces vigente Plan General de Contabilidad de 1973, siguiendo la estela del modelo francés de 1982 que incluía el valor añadido como una de sus magnitudes relevantes. Así, según Barea (1986, p. 609) con la revisión del Plan General de Contabilidad se perseguían dos nuevas finalidades: "la determinación del valor añadido por la empresa y su distribución entre los diferentes agentes económicos".

No obstante, tanto en los sucesivos borradores, como en el texto definitivo publicado mediante el Real Decreto 1643/1990, de 20 de diciembre (BOE de 27 de diciembre), por el que se aprueba el Plan General de Contabilidad, se eliminó de la información de carácter obligatorio cualquier mención al EVA/ERGD, no disponiéndose aún de una explicación convincente o por

\footnotetext{
${ }^{1}$ Conectado con lo señalado, cabe hacer una especial mención a la figura del bilan social, una iniciativa del Ministerio de Trabajo de Francia introducida en su Código del Trabajo, por medio del artículo 438-3 del Code du Travail, añadido por el artículo $1^{\circ}$ de la Loi 77-769 du 12 juillet 1977. Destaca que, a pesar del caudal de datos que las empresas de más de 300 trabajadores deben aportar para cumplimentar el citado informe (datos requeridos en la actualidad desde el artículo 2323-8 hasta el 2323-12-2 del Code du Travail), el valor añadido figure como una magnitud más, sin otorgarle especial importancia.

Procede comentar que en algunos entornos se hacer equivaler la noción de balance social a la de estado de valor añadido (véase, por ejemplo, Perera, 2014). No obstante, en términos estrictos, mientras el primero incorpora datos numéricos no monetarios además de información cualitativa, el EVA tiene un carácter fundamentalmente monetario. En el presente trabajo se ha optado por esta segunda interpretación.
}

Déniz Mayor, J. J., Arteaga Arzola, L. M., y Manrique de Lara Peñate, C. 
lo menos de un relato que ofrezca evidencias de las razones que llevaron al Instituto de Contabilidad y Auditoría de Cuentas a tomar esa decisión. Una excepción de relieve es el trabajo de Larrinaga (2001) en el que se apunta a la reorientación producida en los primeros gobiernos de Felipe González, al pasar de un primer gabinete socialdemócrata (1982-1985) a un segundo de carácter liberal (1986 en adelante), en el que se produce una actividad desreguladora, liberalizadora y de privatización más intensa; es decir de un modelo donde:

el valor añadido era posible y la coalición de intereses que esta cuenta representa estaba comprometida con la racionalidad de la intervención del gobierno [... a otro...] donde los empleados y toda la empresa están supeditados jerárquicamente a las fuerzas del mercado financiero, negándose así las condiciones de posibilidad del EVA. (p. 60)
Así, la única mención a la noción de valor añadido (salvo la alusión al reflejo contable de los impuestos sobre el mismo) se recoge en la última nota de la memoria del citado Plan contable de 1990. Esta nota está referida a una Cuenta de pérdidas y ganancias analítica, incluida en la memoria, en la que se determinan diversos resultados parciales, siendo uno de ellos el denominado valor añadido de la empresa, solución que presenta el claro inconveniente del carácter voluntario de su presentación ${ }^{1}$.

A pesar del escaso arraigo del EVA/ERGD en el mundo empresarial español, algunas compañías presentaron dicho estado en sus informes anuales. Uno de los casos más destacados fue el de Telefónica (de titularidad pública en aquellos momentos) que en su memoria anual de 1985 presentaba dentro del capítulo III “Economía y Finanzas” (Telefónica, 1985, p. 62) un EVA referido al último lustro (Tabla 2).

\footnotetext{
${ }^{1}$ Parece oportuno reiterar que, a pesar de lo recogido en algunos trabajos académicos, ni en el plan contable francés de la época ni en su homólogo español, aparece representado modelo alguno de EVA/ERGD; quizás la alusión al cálculo del valor añadido como uno de los escalones del resultado contable haya motivado tal confusión.
} 
Tabla 2

Valor añadido de la empresa Telefónica (años 1981-1985)

\begin{tabular}{|c|c|c|c|c|c|}
\hline \multicolumn{6}{|c|}{$\begin{array}{c}\text { VALOR AÑADIDO DEL ÚLTIMO QUINQUENIO } \\
\text { (Millones de Pesetas) }\end{array}$} \\
\hline & 1981 & 1982 & 1983 & 1984 & 1985 \\
\hline \multirow{3}{*}{$\begin{array}{l}\text { Ingresos Totales (I) } \\
\text { Trab. Sum. y Serv. Exter. } \\
\text { Gastos diversos de gestión }\end{array}$} & +262.677 & +310.829 & +368.542 & +428.865 & +481.081 \\
\hline & 19.090 & 25.443 & 30.540 & 35.375 & 41.240 \\
\hline & 848 & 1.006 & 1.075 & 1.744 & 2.165 \\
\hline Total devengos al exterior & -19.938 & -26.449 & -31.615 & -37.119 & -43.405 \\
\hline \multirow{2}{*}{$\begin{array}{l}\text { Valor añadido } \\
\text { Retribución factor trabajo }\end{array}$} & 242.739 & 284.380 & 336.927 & 391.746 & 437.676 \\
\hline & 99.134 & 117.439 & 132.765 & 144.686 & 159.572 \\
\hline Retribución factor capital & 69.917 & 79.142 & 90.885 & 108.031 & 115.859 \\
\hline - Capital propio & 23.497 & 26.434 & 27.095 & 32.214 & 38.649 \\
\hline $\begin{array}{l}\text { - Capital ajeno } \\
\text { Impuestos }\end{array}$ & 46.420 & 52.708 & 63.790 & 75.817 & 77.210 \\
\hline Impuestos & 12.269 & 14.845 & 17.958 & 21.117 & 23.710 \\
\hline $\begin{array}{l}\text { Sostenimiento de los medios de producción (dotación a } \\
\text { amortizaciones, previsiones, reservas, etc.) }\end{array}$ & 61.419 & 72.954 & 95.319 & 117.912 & 138.535 \\
\hline
\end{tabular}

Fuente: Memoria anual. Compañía Telefónica Nacional de España (Telefónica, 1985, p. 62).

Así, el valor añadido se calculaba como diferencia entre los ingresos totales ${ }^{1}$, que incluyen los trabajos realizados por la empresa para su inmovilizado, y los gastos externos de la entidad. La cifra resultante se reparte entre cuatro grupos sociales considerados importantes para los administradores de la sociedad: el Factor trabajo, que incluye salarios y demás gastos sociales; el Factor capital, discriminando aquí entre la retribución al capital propio de la empresa, por medio de dividendos a accionistas, y la correspondiente al capital ajeno, en forma de intereses devengados; el Estado, que equivale a lo que aporta la empresa directamente a través de los impuestos (aunque sin precisar si, además del impuesto sobre beneficios, se incluyen otras cargas tributarias); y para finalizar, la propia empresa, es decir, las rentas que garantizan el sostenimiento de los medios de producción, por medio de dotaciones a la amortización ${ }^{2}$, las previsiones ${ }^{3}$ y las reservas.

Con posterioridad y en el contexto del debate sobre la reforma de la regulación contable española para adaptarla a los avances que iban teniendo lugar en la normativa internacional, en el denominado Libro Blanco

\footnotetext{
${ }^{1}$ De la propia denominación de "Ingresos totales" cabría interpretar que, además del valor de la producción y otros ingresos afectos a la explotación, se estaría incluyendo el resto de ingresos generados en la empresa con independencia de su naturaleza o función, con lo que quizás la propia denominación de "valor añadido" no sea del todo precisa.

${ }^{2}$ En el Apéndice B se discutirá sobre la inclusión o no de las amortizaciones en el cómputo y la formulación de los conceptos de "valor bruto" $\mathrm{y}$ "valor neto".

${ }^{3}$ Este es un concepto incluido en el Plan General de Contabilidad de 1973, en alusión a determinadas retenciones de resultados con un destino específico a la cobertura de riesgos.
} 
para la Reforma de la Contabilidad en España (ICAC, 2002, p. 160) se propuso que, para aquellas grandes empresas que tuviesen un impacto relevante en el desarrollo de la economía nacional o de una región determinada, se incluyese una medida de la contribución a las grandes magnitudes del territorio de referencia, como por ejemplo al PIB (valor añadido) o a la renta generada, el empleo indirecto creado en el área de influencia o la contribución neta con los tributos pagados al sostenimiento de las cargas públicas.

Finalmente, en el vigente Plan General de Contabilidad, regulado mediante el Real Decreto 1514/2007, de 16 de diciembre (BOE de 20 de diciembre), por el que se aprueba el Plan General de Contabilidad no se hace referencia alguna al concepto de valor añadido en los términos tratados en el presente trabajo.

Debe tenerse presente que, desde el punto de vista de la regulación contable, la Norma Internacional de Contabilidad (NIC) 1 (International Accounting Standard Board, 2006), declaró el carácter no obligatorio del EVA/ERGD al indicar que:

Muchas entidades también presentan, adicionalmente a sus estados financieros, informes y estados tales como informes medioambientales y estados del valor añadido, particularmente en sectores industriales en los que los factores del medioambiente resultan significativos $\mathrm{y}$ donde los trabajadores se consideran un importante grupo de usuarios. Estos informes y estados, presentados adicionalmente a los estados financieros, quedan fuera del alcance de las NIIF [Normas Internacionales de Información Financiera] (párr. 10).
Por consiguiente, el EVA/ERGD estaría fuera de los límites de la regulación contable internacional, posiblemente por considerar que los principales destinatarios de informes como los expuestos no son ni inversores ni prestamistas.

Por otra parte, el EVA/ERGD no ha sido ajeno a críticas que podrían explicar su declive más allá del argumento del cambio de orientación política producido en los gobiernos nacionales (Burchell et al., 1985, Larrinaga, 2001).

Entre las principales limitaciones aducidas en torno al EVA/ERGD se incluye la posibilidad de generar confusión con la Cuenta de pérdidas y ganancias (Morley, 1979, p. 624, Pong y Mitchell, 2005, pp. 176177), pues, ¿cómo cabría interpretar que el valor añadido fuese positivo mientras el resultado contable arroja cifras negativas? ¿no cabría la posibilidad de que los grupos de interés desconfiasen de este informe y sospechasen de la existencia de manipulación contable? Aunque autores como van Staden y Vorster (1998: 347) no encuentran evidencias de que modelos basados en el EVA tengan un poder predictivo, otros como RiahiBelkaoui y Picur (1994, p. 59), Belkaoui y Picur (1999, p. 71), Вao y Bao (1998, p. 262), o Veras et al. (2015, p. 67), observan que el valor añadido explica mejor los rendimientos bursátiles que enfoques sustentados en la cuenta de resultados o los flujos de efectivo.

Otro elemento a considerar es el riesgo de gestión ineficiente (Morley 1979, p. 624). Es factible que, frente a la opción de subcontratar todos o parte de los procesos, se optase por mantener la producción en el seno de la empresa con el propósito de mostrar una cifra de rentas laborales más elevada y reducir la conflictividad social. Pong y Mitchell (2005, p. 177) observan que el sistema capitalista define unas reglas claras bajo las cuales aquellas empresas con mayores 
beneficios serán las mejor posicionadas y las que sobrevivirán a largo plazo, lo cual puede afectar negativamente a la noción de equidad distributiva $\mathrm{y}$, de paso, explicar el escaso arraigo de los EVA/ERGD, porque quizás estos documentos no estarían informando sobre algo que preocupe al inversor tradicional. Probablemente, en algo deba haber contribuido la visión neoliberal predominante desde finales de los años ochenta, basada en la maximización del valor para el accionista, donde la retribución a otros factores es considerada un coste o una reducción de su riqueza (Haller et al., 2018, p. 69).

En sentido contrario, una crítica adicional está relacionada con los procesos de externalización de la mano de obra, bien mediante la subcontratación de operarios (vía empresas de trabajo temporal) o de actividades a otras compañías o bien mediante el recurso a la figura de los “falsos autónomos”. Así, procede hacer mención a la controversia suscitada tras la implantación de nuevos modelos de negocios sustentados en la denominada "economía colaborativa”, siendo uno de los casos más llamativos la “uberización” (Nerinckx, 2016, Fleming, 2017). En conexión con lo anterior, los avances en la robótica y la inteligencia artificial y la consiguiente sustitución de las personas por máquinas (físicas y virtuales) en tareas hasta hace poco impensables, también están teniendo su influencia en la configuración del EVA/ERGD al sustituir las rentas salariales como receptoras de renta, por las amortizaciones de activos, como generadoras de renta o como rentas retenidas según el modelo de estimación (neto o bruto) que se utilice (ver más adelante). Tanto en el caso de la externalización como en el de robotización, se estaría rompiendo con la idea de la "gran familia" de Nicklish y sus seguidores y quizás con una de las principales justificaciones del EVA/ERGD como visualización de las relaciones entre trabajo y capital.

La inexistencia de un modelo estandarizado de presentación que facilite la comprensión y comparación de informes es otro de los inconvenientes aducidos tanto por Morley (1979, p. 625) en su momento, como en la actualidad (Haller et al., 2018), lo que podría ser indicativo de los escasos avances producidos hasta la fecha. Tal es así que parte de la literatura sobre el EVA/ERGD parece centrarse más en los formatos de presentación del informe, que en los aspectos valorativos o de análisis e interpretación de los datos.

No obstante, este inconveniente se salva, aunque parcialmente, gracias a las orientaciones en materia de información sobre sostenibilidad de la Global Reporting Initiative (GRI, 2014, 2016). Entre los contenidos básicos del informe propuesto por la GRI se encuentra una categoría denominada "Economía”, en la que se da cuenta, entre otros asuntos, del desempeño económico de la entidad (G4-EC1, en la versión de 2014; GRI 201, en la versión de 2016). En ese apartado se muestra el valor económico directo generado y distribuido, reseñándose los ingresos de la compañía y cómo se han distribuido, entre costes operacionales, salarios y beneficios de los empleados, pagos a proveedores de capital, pagos al gobierno (por país) e inversiones en la comunidad.

Nótese que si bien en el EVA clásico la base de reparto se obtiene de la diferencia entre el valor de la producción (o, en su caso, venta) de bienes y servicios y el valor de las adquisiciones exteriores necesarias para obtener dicha producción (o, en su caso, venta), en el modelo de la GRI se parte de todos los ingresos generados en el periodo y no del valor añadido. Por tanto, los proveedores de bienes y servicios son considerados como un grupo de interés más y no como 
un input. En consecuencia, el valor económico generado según la GRI no se correspondería con el valor añadido en un sentido estricto. Se podría decir que más que un EVA, el modelo de la GRI es un estado de reparto de ingresos generados (que no de rentas). Asimismo, en el esquema básico de la GRI no se distingue entre dividendos e intereses abonados, sino que las rentas a los inversores financieros aparecen agregadas en una sola cifra, con lo que no es posible comparar las rentas salariales con las del capital-propiedad, uno de los aspectos claves del EVA/ERGD. No queda claro si tal decisión ha sido intencionada o no.

Ahora bien, aunque se siga el modelo de la GRI pueden observarse diferencias en la presentación. A título ilustrativo cabe citar los informes de Iberdrola de 2018 e Inditex de 2017 (ver Tablas 3 y 4). Mientras el primero se muestra de acuerdo con el principio del devengo, el segundo lo hace bajo el principio de caja o efectivo, con un Estado de flujos de caja social. En cualquier caso, todos estos informes se caracterizan por no explicar cómo se han obtenido las cifras presentadas $^{1}$.

\section{Tabla 3}

Valor económico directo generado y distribuido en Iberdrola (2016-2018)

\begin{tabular}{l|r|r|r}
$\mathbf{2 0 1 - 1}$ & \multicolumn{5}{|l}{} \\
\hline $\begin{array}{l}\text { Valor económico directo generado, distribuido y retenido } \\
\text { (millones } \boldsymbol{~} \text { ) }\end{array}$ & $\mathbf{2 0 1 8}$ & $\mathbf{2 0 1 7}$ & $\mathbf{2 0 1 6}$ \\
\hline Total Iberdrola & 36.273 & 32.714 & 30.706 \\
\hline Ingresos (ventas y otros ingresos) & 22.433 & 20.446 & 18.588 \\
\hline Costes operativos & 2.387 & 2.517 & 2.260 \\
\hline Retribución a empleados (sin coste seguridad social empresa) & 2.402 & 2.916 & 2.692 \\
\hline Pagos a proveedores de capital & 3.096 & 2.723 & 2.740 \\
\hline Pagos a Administraciones Públicas & & & \\
\hline Inversiones en beneficio de la comunidad (verificado de acuerdo al & 54 & 63 & 36 \\
\hline Modelo LBG) & 5.901 & 4.049 & 4.390 \\
\hline Valor económico retenido
\end{tabular}

Fuente: Estado de información no financiera. Informe de sostenibilidad. Ejercicio 2018 (Iberdrola, 2019, p. 71).

\footnotetext{
${ }^{1}$ Incluso, si se entra en matices, el apartado de Retribuciones a empleados (sin coste seguridad social empresa) del informe de Iberdrola se presenta sin incluir los costes de seguridad social a cargo de la empresa, a pesar de que la GRI indica que en esta partida recoge, además de los salarios de los empleados, las cantidades que se abonan a instituciones gubernamentales (impuestos, exacciones y fondos para desempleo) por cuenta de los empleados y las aportaciones sociales periódicas (pensiones, seguros, vehículos de empresa y salud privada), entre otras.
} 


\section{Tabla 4}

Cash flow social del grupo Inditex (2016-2017)

\begin{tabular}{lrr}
$\begin{array}{l}\text { CASH FLOW SOCIAL } \\
\text { (millones de euros) }\end{array}$ & $\mathbf{2 0 1 7}$ & $\mathbf{2 0 1 6}$ \\
\hline $\begin{array}{l}\text { Efectivo neto recibido por la venta } \\
\text { de productos y servicios }\end{array}$ & 25.336 & 23.311 \\
\hline Flujo recibido de inversiones financieras & 26 & 21 \\
\hline $\begin{array}{lrr}\text { Efectivo recibido por ventas de activos } \\
\text { Total flujo de valor añadido }\end{array}$ & $\mathbf{2 5 . 7 4 3}$ & $\mathbf{2 3 . 3 3 2}$ \\
\hline Distribución del flujo de valor añadido & 3.961 & 3.643 \\
\hline Remuneración a empleados por sus servicios & 1.029 & 798 \\
\hline Impuesto sobre beneficios pagado & -47 & 53 \\
\hline Devolución de deuda financiera & 2.127 & 1.871 \\
\hline Dividendos entregados a los accionistas & 48 & 40 \\
\hline Inversión en programas sociales & 759 & 833 \\
\hline Caja retenida para crecimiento futuro & & \\
\hline $\begin{array}{l}\text { Pagos realizados fuera del Grupo por compra } \\
\text { de mercancía, materias primas y servicios }\end{array}$ & 16.088 & 14.649 \\
\hline $\begin{array}{l}\text { Pagos realizados para inversiones en nuevos } \\
\text { activos productivos }\end{array}$ & 1.778 & 1.445 \\
\hline Total distribución de flujo de valor añadido & $\mathbf{2 5 . 7 4 3}$ & $\mathbf{2 3 . 3 3 2}$ \\
\hline
\end{tabular}

Fuente: Balance de sostenibilidad 2017, por Grupo Inditex (2018).

Otra dificultad atribuida al EVA/ERGD es que el proceso de distribución del valor añadido no necesariamente está directamente relacionado con los partícipes que han contribuido a su obtención, surgiendo dudas acerca de la propia delimitación de quién puede ser calificado de partícipe y quién no (Morley 1979, pp. 623-624). Si la idea básica es que la renta debe ser repartida entre los que la han generado, puede no quedar claro, por ejemplo, en qué ha contribuido el gobierno a la obtención de la renta, sobre todo cuando su participación no está directamente asociada al valor añadido sino al resultado contable (ajustado por las diferencias temporarias y permanentes correspondientes, más las deducciones y bonificaciones que procedan). Cómo se indicó antes, incluso en el modelo propugnado por la GRI los proveedores de bienes y servicios son considerados un grupo de interés relevante mientras que en los modelos clásicos no, quizás por existir un mayor interés no por cómo se genera la renta, sino a quién se distribuye, dada la preocupación de dicha organización por la cadena de suministro y la conflictividad asociada a las desigualdades entre países. También, y siguiendo con el modelo de la GRI, también cabría cuestionarse en qué medida la sociedad en general y las diferentes comunidades en particular han contribuido a la generación de la renta como para figurar como destinatarios de la misma.

Aunque en su momento se aducía como inconveniente los costes de formulación del estado contable (Morley 1979, p. 625), en la actualidad pueden considerarse irrelevantes. Es más, debido a los desarrollos acaecidos en materia de información financiera, el usuario puede
Déniz Mayor, J. J., Arteaga Arzola, L. M., y Manrique de Lara Peñate, C.
Vol. 7, núm. 19 / enero - abril del 2022 DOI: https://doi.org/10.36791/tcg.v7i19.135 
construir su propio EVA/ERGD partiendo directamente de los datos contenidos en las cuentas anuales, tal y como se expondrá a continuación. En el estudio realizado por Stainbank (2009, p. 144) con directores financieros de empresas sudafricanas, uno de los argumentos adversos al EVA fue precisamente que, en cualquier caso, los datos podían ser obtenidos directamente de los estados financieros. Esta simple pero importante observación podría solventarse si dicho informe aportase, nunca mejor dicho, un "valor añadido” al análisis, por ejemplo, incluyendo la distribución salarial por categorías y género, o los tributos y subvenciones por áreas geográficas. Por otra parte, Haller et al. (2018, pp. 776-777) observan que los EVA publicados por las empresas suelen carecer de precisión conceptual, claridad y utilidad, llegándose incluso a aplicar técnicas de ofuscación que impiden conciliar los datos aportados con los que figuran registrados en los estados financieros.

Por último, la información contenida en dicho estado no sugiere que sea un mecanismo apto para resolver la naturaleza conflictiva de la negociación colectiva y favorecer la cooperación, ya que en términos relativos los trabajadores son generalmente el colectivo con mayor peso en el EVA/ERGD y los demás grupos de interés podrían argumentar una posición desfavorecida. Por eso no ha sido usado por los sindicatos en la negociación colectiva (Pong y Mitchell, 2005, p. 194). Nótese que incluso en el modelo de la GRI no se explicita la conveniencia de separar entre retribuciones del personal y remuneraciones de la alta dirección y del consejo, como sí se propone, por ejemplo, en la Resolución Técnica FACPCE 36, sobre balance social, emitida en Argentina (CPCECABA, 2013). Esto es especialmente relevante pues en países como España la brecha salarial entre los trabajadores y la alta dirección y el consejo se ha ido agrandando con el paso del tiempo, con independencia de la situación económica (Fernández, 03 de mayo de 2015, Vélez, 08 de mayo de 2019, ICSA Grupo, 2020) e, incluso, sin que exista una correlación entre la remuneración de los consejeros ejecutivos y la cotización de las empresas (Gómez, 2019, p. 152).

Asimismo, y quizás sea lo más interesante, en los modelos conocidos de EVA/ERGD se omiten los beneficios por tenencia de acciones y los incentivos basados en opciones sobre acciones: aunque no se percibiesen dividendos, los accionistas (o en su caso directivos) obtienen rentas implícitas gracias la evolución del mercado que pueden materializarse en caso de venta, que no son visibles en el dicho estado ${ }^{1}$ (Pong y Mitchell, 2005, pp. 189-190). Aunque también es cierto que podría hacer visible el creciente peso de las retribuciones monetarias de los altos directivos y administradores, si se llevase a cabo la correspondiente diferenciación informativa entre trabajadores y la cúspide de la organización. A este respecto, procede señalar que en la Directiva (UE) 2017/828, de 17 de mayo de 2017, por la que se modifica la Directiva 2007/36/CE en lo que respecta al fomento de la implicación a largo plazo de los accionistas (párrs. 28 y 29 de los considerandos) se ha puesto de manifiesto la preocupación del Parlamento Europeo y del Consejo por el riesgo de ausencia de correlación entre la remuneración los miembros del órgano de administración de las sociedades cotizadas y su desempeño como tales, así como por la inexistencia de una información clara, comprensible y comparable,

\footnotetext{
${ }^{1}$ En el estudio de Pong y Mitchell para el periodo 1994-2003 la relación renta trabajadores / dividendos calculada según el EVA era de 8,1 a 1, pero si se consideraba la variación en la capitalización bursátil en vez de los dividendos, la relación bajaba a 1,8 a 1.
} 
acerca de la retribución de los consejeros. Además, en España recientemente la Comisión Nacional del Mercado de Valores (2021) estaba trabajando en una modificación de la circular que regula el informe anual de remuneraciones de los consejeros (IARC), al objeto de que se incluyese

un cuadro en el que se pueda observar la evolución durante los últimos cinco años de la variación relativa anual de la remuneración anual de cada consejero, de la remuneración anual media de empleados no consejeros y del resultado anual de la entidad. (p.38)

\section{Calculando el valor añadido / renta generada}

A diferencia de lo acontecido en el ámbito de la Contabilidad Nacional, donde se dispone de un modelo de sistema de cuentas nacionales estandarizado (véase, por ejemplo, el SEC 2010), la metodología de diseño y formulación del EVA/ERGD ha sido una cuestión controvertida en el contexto de la Contabilidad Financiera, sin que se hayan consensuado unas normas específicas para calcular la magnitud valor añadido y, una vez obtenido éste, reflejar su distribución entre los distintos participes, lo que se ha traducido en propuestas como las de Gonzalo y Pérez (2017) para que se aborde su normalización. Existe bastante literatura en torno a la estructura de este informe (por ejemplo, Gorosito, 1997, Pastor et al., 2011, Azcárate y Fernández, 2013, Haller y van Staden, 2014), por lo que en la presente sección se abordará su contenido desde una perspectiva analítica. En el Apéndice B se incluyen diferentes apreciaciones y observaciones en torno a posibles aspectos interpretativos acerca de la ubicación y/o agregación de determinadas partidas.

Déniz Mayor, J. J., Arteaga Arzola, L. M., y Manrique de Lara Peñate, C.
Las diferentes magnitudes que conforman el resultado contable pueden ser delimitadas, de forma simplificada y en principio, de acuerdo con la siguiente expresión:

$$
R C O=I V-C+V E x-A D-G P-G F I-T a x
$$

donde:

RCO: Resultado contable ordinario

IV: Ingresos por ventas

C: Compras de bienes y servicios comerciales

VEx: Variación de existencias

$A D$ : Amortizaciones y deterioros

GP: Gastos de personal

GFI: Gastos financieros por intereses

Tax: Impuestos

Si se sustraen los dividendos (Div), se obtendría el resultado retenido o renta retenida $(R R)$. Es decir:

$$
R R=I V-C+V E x-A D-G P-G F I-T a x-D i v
$$

Si a continuación, se realizan determinados cambios de posición, se obtienen las dos expresiones que conforman sendos enfoques básicos de cálculo del valor añadido, bien como información de gestión (centrada en su obtención), bien como información social (centrada en la distribución entre los grupos de interés tradicionales):

$V A=I V-C+V E x-A D=G P+G F I+T a x+D i v+R R$

Así, en el segundo caso, es obvio que la variable GP se asocia a las rentas recibidas por los trabajadores (incluyendo las de carácter indirecto como las cotizaciones a la seguridad social o las aportaciones a planes de pensiones), mientras que GFI alude a las transferidas a los prestamistas, Tax al gobierno, Div a 
los accionistas y $R R$, también a los accionistas, aunque retenidas en la propia empresa ${ }^{1}$. Como señala Bagieńska (2016, p. 97), aunque el valor añadido no puede ser la única medida del desempeño, "el lado derecho de la ecuación tiene un gran valor cognitivo, desde que muestra al lector las direcciones de la distribución de los valores obtenidos."

La propia noción de valor añadido está sujeta a matices en virtud de la ubicación de las diferentes partidas a un lado o al otro de la expresión. Así, cabe hablar en primera instancia de valor añadido bruto $(V A B)$ y valor añadido neto (VAN) (ceteris paribus), atendiendo a la ubicación de las amortizaciones y deterioros, bien como renta retenida en la empresa, bien como componente de los costes de producción:

$$
\begin{gathered}
V A B=I V-C+V E x=G P+G F I+\text { Tax }+ \text { Div }+[R R+ \\
A D] \\
V A N=I V-C+V E x-A D=G P+G F I+\text { Tax }+ \text { Div }+ \\
R R
\end{gathered}
$$

Otra distinción es la basada en los enfoques de las compras (C) y del coste de las ventas (CV) (ceteris paribus), según se considere la variación de existencias como menor valor de las rentas retenidas o como integrante del coste de producción, es decir:

$$
\begin{gathered}
V A(C)=I V-C-A D=G P+G F I+\text { Tax }+ \text { Div }+[R R- \\
V E x] \\
V A(C V)=I V-C+V E x-A D=G P+G F I+\text { Tax }+ \text { Div } \\
+R R
\end{gathered}
$$

En la entidad pueden producirse rentas adicionales al valor añadido, susceptibles de distribución entre los grupos de interés. Así, existen ingresos y gastos que junto con el valor añadido contribuyen a la generación de rentas, tales como los rendimientos de las inversiones financieras, rentas de la propiedad, beneficios y pérdidas por enajenación de activos no corrientes e instrumentos financieros, plusvalías y minusvalías por mera tenencia de activos disponibles para la venta, ingresos por subvenciones de capital recibidas, gastos extraordinarios o resultados de operaciones de combinaciones de negocios, etc. Un ejemplo se encuentra en las sociedades de cartera, donde los rendimientos financieros tienen un peso relevante en los ingresos de la entidad y que al constituir rentas de capital y no de la actividad productiva quedarían fuera del EVA (en la práctica se reconocen contablemente como integrantes de la cifra neta de negocios). Esto puede dar lugar a la paradoja de que las rentas distribuidas sean mayores que el valor añadido generado, toda vez que, por un mero cuadre contable, todas las rentas generadas deben ser igual a las rentas distribuidas.

Un modelo que no tenga en cuenta dichas partidas se presumirá como insuficiente para mostrar la realidad de la generación y distribución de las rentas, lo que conlleva expandir la noción de valor añadido. Por lo tanto, el valor añadido no sería más que una de las diferentes clases de rentas generadas, cuya agregación conformaría el total de rentas generadas y distribuidas del ejercicio (RGDE). Así, si se considera la siguiente versión ampliada de cuenta de resultados:

$R C E=I V-C+V E x-A D-G P-G F I-T a x+S+O I-$
$O G$ donde:

\section{RCE: Resultado contable del ejercicio}

S: Subvenciones y otras ayudas públicas imputadas al resultado

OI: Otros ingresos

OG: Otros gastos

\footnotetext{
${ }^{1}$ En el Apéndice B se matiza y detalla el contenido de estas partidas.
} 
Entonces, suponiendo que se adopta el enfoque del coste de la venta y de la renta neta:

$$
\begin{gathered}
R G D E=I V-C+V E x-A D+S+O I-O G=G P+ \\
G F I+T a x+D i v+R R a e
\end{gathered}
$$

donde:

RRae: Renta retenida ajustada partiendo del resultado del ejercicio

Entrando en el ámbito de los matices, cabe reseñar que en el denominado "método alemán" (recogido por Reichman y Lange, 1980, p. 529), al representar los fondos destinados al gobierno, estos figuran minorados por las subvenciones recibidas, lo que permite reflejar en un mayor grado la imagen fiel de la distribución a este grupo de interés, dado el posible carácter controvertido de esta figura (Gracia, 2013). Considerando el modelo RGDE, se puede presentar una versión alternativa donde las transferencias al gobierno se muestren netas de subvenciones, suponiendo que se adopta el enfoque del coste de la venta y de la renta neta:

$$
\begin{gathered}
R G D E=I V-C+V E x-A D+O I-O G=G P+G F I+ \\
{[\text { Tax }-S]+\text { Div }+ \text { RRae }}
\end{gathered}
$$

Un refinamiento de los modelos anteriores consistiría en considerar no solo los ingresos y gastos imputados al resultado contable, sino además los aparcados transitoriamente en el patrimonio neto, mientras se verifican las condiciones pertinentes para su traslación al resultado, cuya agregación conforma el resultado global. De esta forma, cabría distinguir entre Rentas generadas y distribuidas del ejercicio (RGDE) y Rentas generadas y distribuidas globales o totales (RGDT) (ceteris paribus). Si

$$
R C T=R C E+A C V+S D L
$$

donde:

\section{RCT: Resultado contable global o total}

ACV: Ajustes por cambio de valor registrados en patrimonio neto durante el ejercicio

SDL: Subvenciones, donaciones y legados recibidos durante el ejercicio e imputados a patrimonio neto

Entonces, suponiendo que se adopta el enfoque del coste de la venta y de la renta neta:

$$
\begin{gathered}
R G D T=I V-C+V E x-A D+S+O I-O G+A C V+ \\
S D L=G P+G F I+T a x+D i v+R R a t
\end{gathered}
$$

donde:

RRat: Renta retenida ajustada partiendo del resultado global

Algunas de las alternativas expuestas han tenido su reflejo en la historia reciente del EVA o, si se prefiere más propiamente, el ERGD. Así, en el modelo de EVA propuesto en The Corporate Report (ASSC, 1975, p. 50) se seguía un enfoque basado en las compras, al excluir las existencias del cómputo del valor añadido, quizás por su conexión inmediata con el impuesto sobre el valor añadido, combinado con el enfoque del valor añadido bruto, pues las amortizaciones se consideraban integrantes de las rentas retenidas.
Déniz Mayor, J. J., Arteaga Arzola, L. M., y Manrique de Lara Peñate, $C$.
Vol. 7, núm. 19 / enero - abril del 2022 DOI: https://doi.org/10.36791/tcg.v7i19.135

Pp. 107-149 
Sin embargo, en el denominado “método alemán” (Reichman y Lange, 1980) se opta por los enfoques del coste de las ventas (al incluir la variación de existencias en el cálculo del valor añadido) y del valor neto (al deducir las amortizaciones del cómputo del valor añadido y no integrarlas en las rentas retenidas). Además, se consideraban todas las rentas generadas en la empresa, no solo el valor añadido (aunque lo denominasen "valor añadido de la empresa", por contraposición al "valor añadido de la actividad”, que no tenía en cuenta las operaciones ajenas a la explotación). Esta orientación se ha mantenido en la actualidad, como lo demuestra el ejemplo de estado de valor añadido del Grupo Volkswagen citado anteriormente (Tabla 1).

En lo que respecta al modelo español, tributario a su vez del francés, recuérdese que ni uno ni otro proponía un EVA, si bien al calcular el valor añadido el PGC de 1990 se parecía al alemán en que seguía el enfoque del coste de la venta, pero al ubicar las amortizaciones, estas quedaban excluidas del cómputo del valor añadido.

De cara a los estudios de caso propuestos en el presente trabajo, se partirá de la noción de rentas generadas a partir del resultado del ejercicio. Suponiendo que se adopta el enfoque del coste de las ventas y de la renta neta:

$$
\begin{gathered}
R G D E=I V-C+V E x+S+O I-A D-O G=G P+ \\
G F I+\text { Tax }+ \text { Div }+ \text { RRae }
\end{gathered}
$$

Si se escoge el segundo término de la expresión:

$$
R G D E=G P+G F I+T a x+D i v+R R a e,
$$

dado que

$$
\text { RRae }=\text { RCE }- \text { Div, }
$$

se puede simplificar la expresión para permitir su fácil tabulación a partir de los datos contables:

$$
R G D E=G P+G F I+T a x+D i v+[R C E-D i v]
$$

Nótese que, como se indicó más arriba, salvo que se pretenda que el EVA/ERGD aporte información adicional a la meramente contenida en los estados contables convencionales (por ejemplo, la distribución salarial por categorías y género) no parece que sea imprescindible disponer de tal informe, aunque sí definir claramente los criterios de reconocimiento y valoración pertinentes para identificar y valorar las rentas realmente percibidas por cada grupo de interés.

\section{Breve análisis comparativo de tres ejemplos de reparto de rentas generadas}

\section{Cómo se obtuvieron los datos y qué metodología se implementó para su análisis}

Para seleccionar las muestras de empresas utilizadas en la comparativa se recurrió a la base de datos SABI (2019) propiedad de la empresa Informa S.A., y gestionada por Bureau van Dijk Electronic Publishing. Esta base de datos recoge informes económicos y financieros de más de un millón de empresas en España.

El criterio de selección se basó en la actividad principal desarrollada por las empresas a analizar (en este caso, automoción, construcción de edificios, y alojamiento), debiendo estar inscritas en España y activas durante todo el periodo de análisis, el cual abarcaba de 2008 a 2019, además de presentar sus cuentas anuales bajo el Plan General de Contabilidad de 2007 en el formato normal. A tal objeto se recurrió a la Clasificación CNAE (2009), centrándose en las sociedades cuyos códigos primarios fuesen los siguientes: 
29. Fabricación de vehículos de motor, remolques y semirremolques

\section{Construcción de edificios}

\section{Hoteles y alojamientos similares}

\section{Alojamientos turísticos y otros} alojamientos de corta estancia

El resultado obtenido tras una búsqueda realizada el 25 de febrero de 2021, fue de 188 sociedades dedicadas a la producción automovilística, 183 a la construcción y 265 al alojamiento.

La razón justificativa de haber seleccionado estos tres sectores radica en su obvia diferenciación en cuanto al peso de la tecnología y la mano de obra. Así mientras el sector de automoción es intensivo en el consumo de inmovilizado; la construcción y el alojamiento hotelero lo son en el uso de mano de obra. Por otra parte, el sector de la construcción fue uno de los damnificados durante la crisis de 2008 y el sector del alojamiento hotelero es considerado estratégico en una economía dependiente del turismo como es la española.

A continuación, y mediante la aplicación STATA 11.2, se extrajeron y adaptaron los datos requeridos para obtener las partidas contables relacionadas con el reparto de las rentas generadas, es decir: Resultado del ejercicio (RCE), Gastos de personal (GP), Gastos por intereses (GFI), Impuestos sobre beneficios y Otros tributos (Tax), Dividendos (Div), Subvenciones y otras ayudas públicas imputadas al resultado (S). Los datos relativos a la cifra de dividendos procedieron del Estado de cambios en el patrimonio neto, mientras que los correspondientes a las restantes partidas se obtuvieron de la Cuenta de pérdidas y ganancias.

Posteriormente, se redactaron, para cada sector analizado, varias tablas que mostrasen para los diferentes ejercicios anuales la distribución de la renta generada entre los grupos de interés y la propia empresa, siguiendo el enfoque neto, tanto en términos absolutos como porcentuales. Asimismo, y para cada sector se elaboraron tablas en las que se mostraba la relación entre subvenciones y tributos, así como entre las propias rentas generadas, en función de si se incluía o no la amortización en los cálculos. Con los datos obtenidos se llevó a cabo un análisis descriptivo y comparativo de las tendencias observadas en las variables propuestas, tanto en términos absolutos como relativos, señalando las similitudes y diferencias entre los sectores analizados.

Entre las principales limitaciones de los ejemplos propuestos se encuentra que al haber extraído directamente los datos alusivos a los gastos de personal de la Cuenta de pérdidas y ganancias, no ha sido posible diferenciar los salarios de los directivos y el consejo de administración del resto de trabajadores de la empresa. Tampoco se dispone de la distribución salarial por géneros. Otra limitación es que las rentas de los accionistas solo abarcan los dividendos percibidos, no así las plusvalías por mera tenencia generadas tras la adquisición de los títulos. Finalmente, cabe reseñar que los datos utilizados se presentan en términos nominales sin deflactar, por lo que se ha obviado el posible impacto de la inflación.

\section{Presentación y análisis de los datos}

En el Apéndice A se expone una estadística descriptiva básica (suma total, media, mediana y percentil 75) del activo, el patrimonio neto, la cifra neta de negocios y el resultado para los años 2008, 2012 y 2019. En 2012 se obtuvo el peor resultado contable medio de la serie estadística para el conjunto de las 628 empresas incluidas en el estudio (-976.001 miles de euros) en comparación con el obtenido al principio de periodo de análisis (776.651 miles de euros) y al final del mismo (2.157.024 miles de euros). También en dicho apéndice se muestra el reparto de las rentas siguiendo el enfoque 
neto (Tablas A2 a A4), la comparativa de impuestos brutos versus impuestos netos (tras considerar el efecto de las subvenciones) (Tabla A5), así como las cifras totales de amortización (Tabla A6), a fin de facilitar al lector el análisis de datos con otros posibles enfoques.

En las siguientes líneas se presentan de manera gráfica las distribuciones de rentas generadas en los sectores de automoción, construcción de edificios y alojamiento hotelero, para el periodo 2008-2019 siguiendo el enfoque neto, esto es, tras deducir de la renta generada bruta las amortizaciones.

De la lectura de las Figuras 1, 2 y 3, cuyos datos se presentan en términos absolutos, parece observarse la existencia de un comportamiento diferenciado en los tres sectores. Así mientras las rentas generadas en las empresas de la muestra del sector de automoción mantuvieron una tendencia estable hasta 2013, con una leve caída en 2012, para después empezar a crecer a partir de 2013; las rentas del sector de la construcción no han hecho sino caer desde 2008, alcanzando su punto más bajo en 2014 para después mantenerse estacionarias hasta 2016 en que se observa un leve repunte. Por último, las compañías del sector de alojamiento hotelero se mantuvieron relativamente estables, con dos leves caídas en 2009 y 2012, comenzando a crecer a partir de
2013 y estabilizándose en 2017. En resumidas cuentas, y desde el punto de vista de un análisis preliminar de tendencias parece que el sector de la construcción ha sido el que peor desempeño ha tenido durante el periodo de análisis y que, en términos absolutos, las rentas del trabajo parecen crecer levemente al final del periodo de análisis. Si se realiza un sencillo análisis de correlaciones con los datos agregados de cada año para un nivel de significación del 1\%, en el caso del sector de automoción existe una relación significativa y positiva entre las rentas generadas y las distribuidas al personal, al gobierno y a la propia empresa, no observándose que sea significativa en las rentas a los prestamistas y a los propietarios. Similares resultados se obtienen en el caso del sector de la construcción, excepto en lo que respecta a las rentas retenidas, donde la correlación no es significativa. Es en el sector de alojamiento, donde todas las correlaciones son significativas con valores positivos, excepto en el caso de las rentas a los prestamistas cuyo coeficiente de correlación es significativo, pero negativo. Como curiosidad, procede comentar, sin perjuicio de otras correlaciones entre variables, que sólo en el caso del sector del alojamiento existe una correlación significativa entre las rentas al personal y las rentas a los propietarios y a la propia empresa, arrojando los coeficientes un valor positivo. 


\section{Figura 1}

Distribución de rentas generadas en el sector de automoción, enfoque neto (miles de euros)

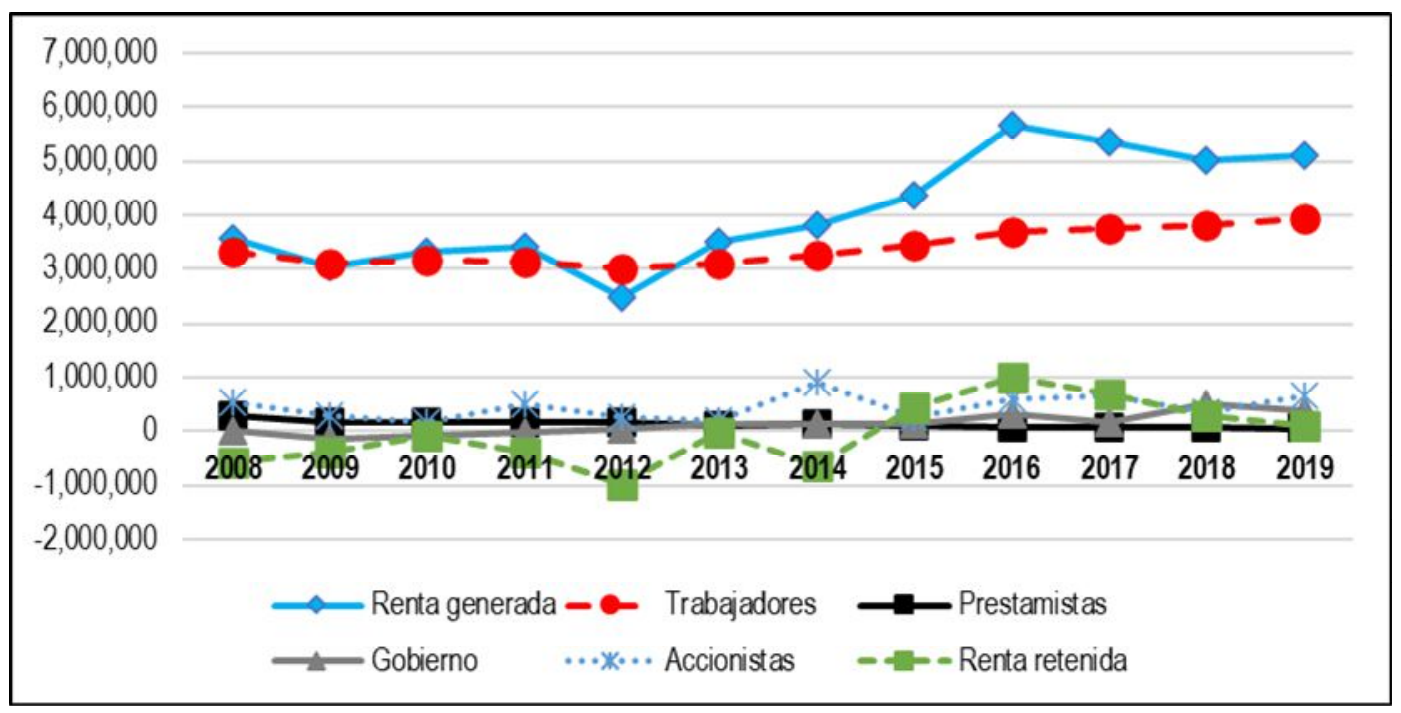

Fuente: Elaboración propia.

\section{Figura 2}

Distribución de rentas generadas en el sector de construcción, enfoque neto (miles de euros)

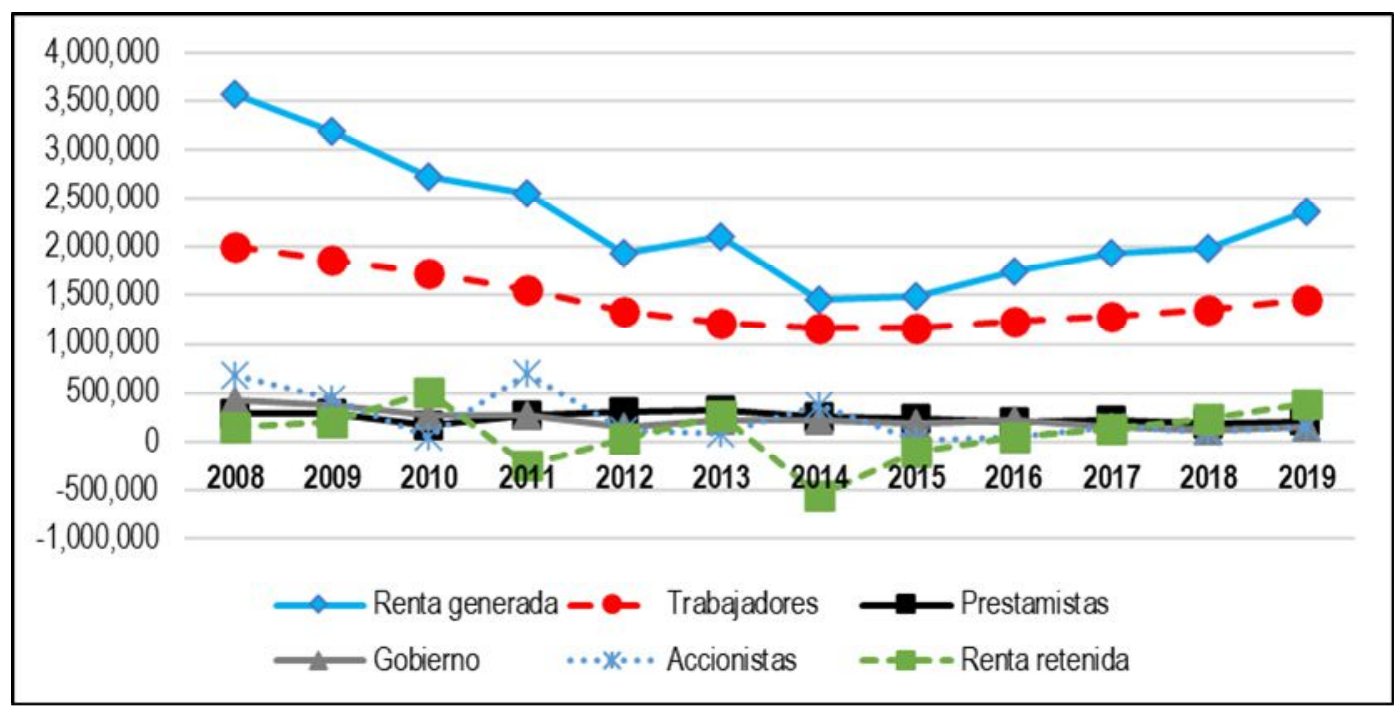

Fuente: Elaboración propia.

Déniz Mayor, J. J., Arteaga Arzola, L. M., y Manrique de Lara Peñate, C.
Vol. 7, núm. 19 / enero - abril del 2022 DOI: https://doi.org/10.36791/tcg.v7i19.135 


\section{Figura 3}

Distribución de rentas generadas en el sector de alojamiento hotelero, enfoque neto (miles de euros)

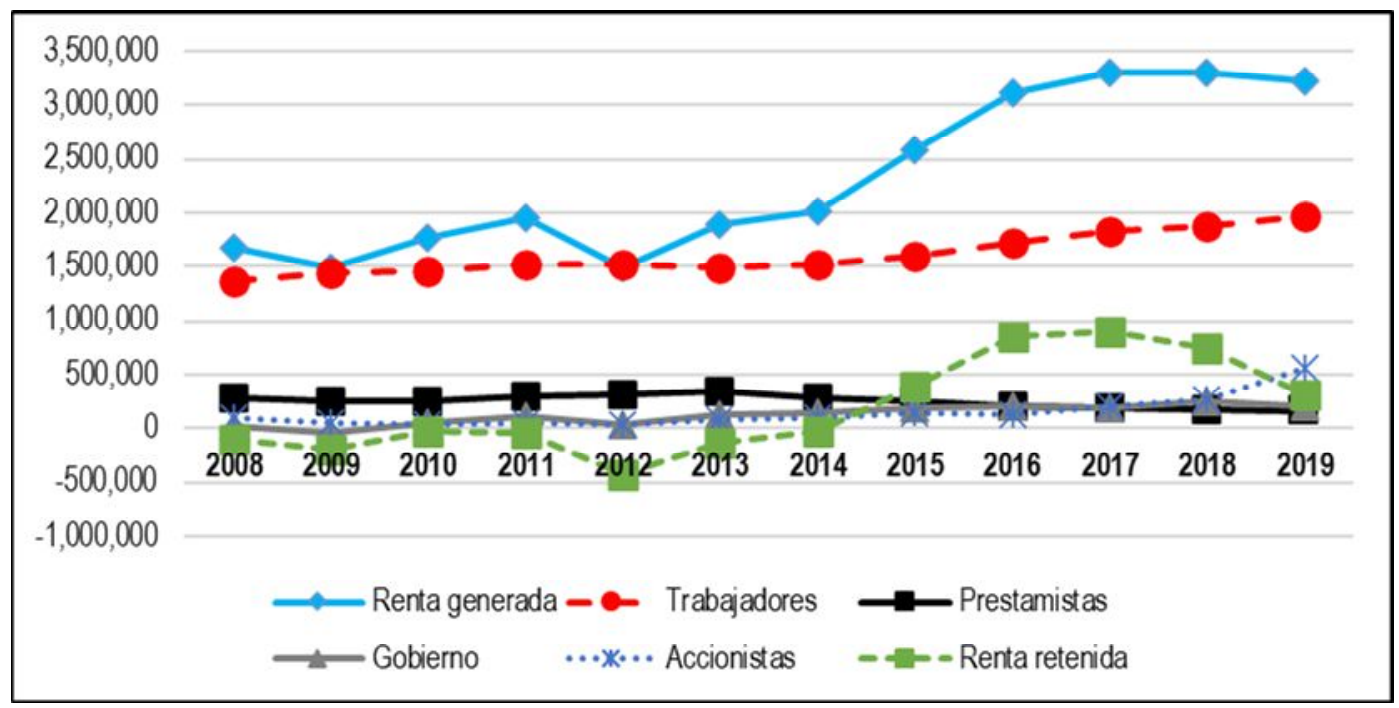

Fuente: Elaboración propia.

Ahora bien, en las Figuras 4, 5 y 6 se muestra la distribución porcentual de las rentas generadas, tomando éstas el valor $100^{1}$. Lo primero que destaca es el peso de las rentas del trabajo frente a los demás grupos de interés y la propia empresa, siendo los años 2009 y 2012 cuando o bien llegan a absorber el $100 \%$ de la renta generada o bien lo superan, excepto en el sector de la construcción. Asimismo, las rentas retenidas muestran un comportamiento claramente adverso pues en determinados periodos sus valores son negativos, indicativo de que se estaría produciendo una transferencia de renta de las propias empresas a los grupos de interés.

\footnotetext{
${ }^{1}$ El cálculo se ha hecho a partir de los datos agregados que se muestran en las tablas del Apéndice A.
} 


\section{Figura 4}

Distribución de rentas generadas en el sector de automoción, enfoque neto (porcentaje)

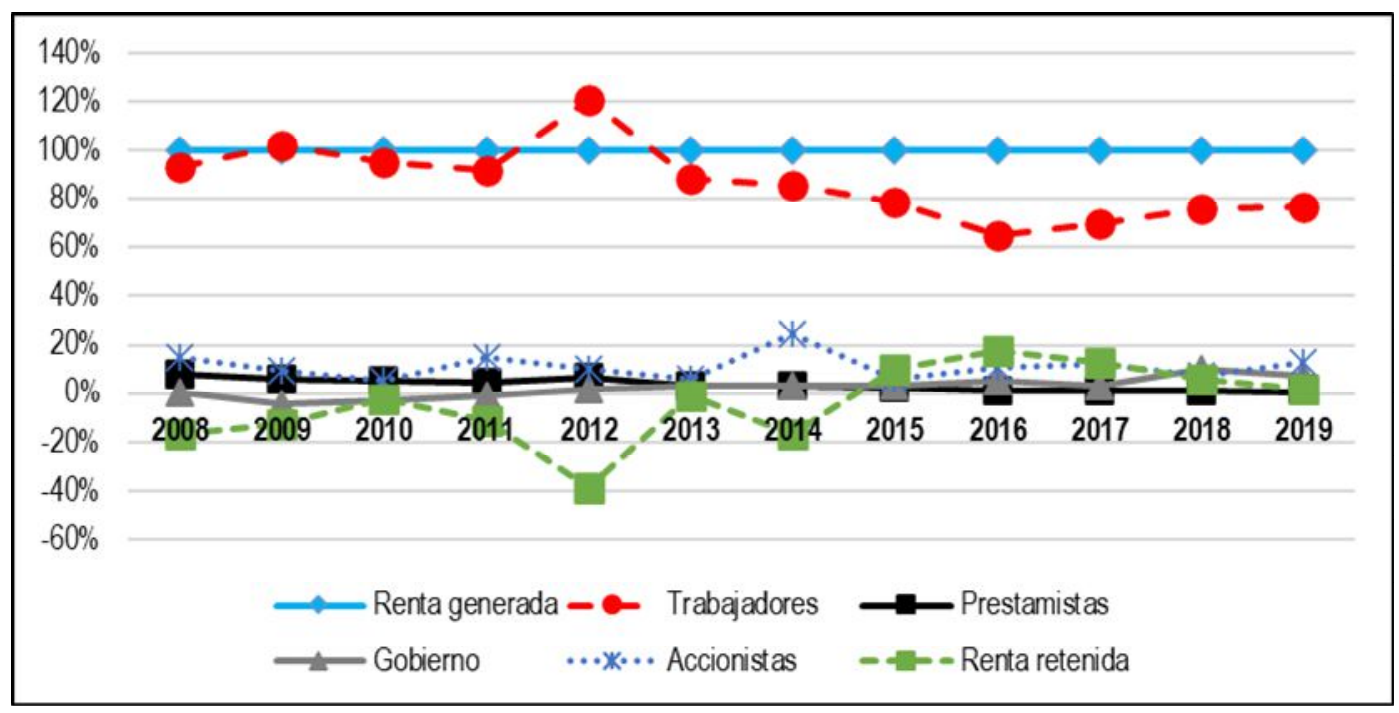

Fuente: Elaboración propia.

\section{Figura 5}

Distribución de rentas generadas en el sector de construcción, enfoque neto (porcentaje)

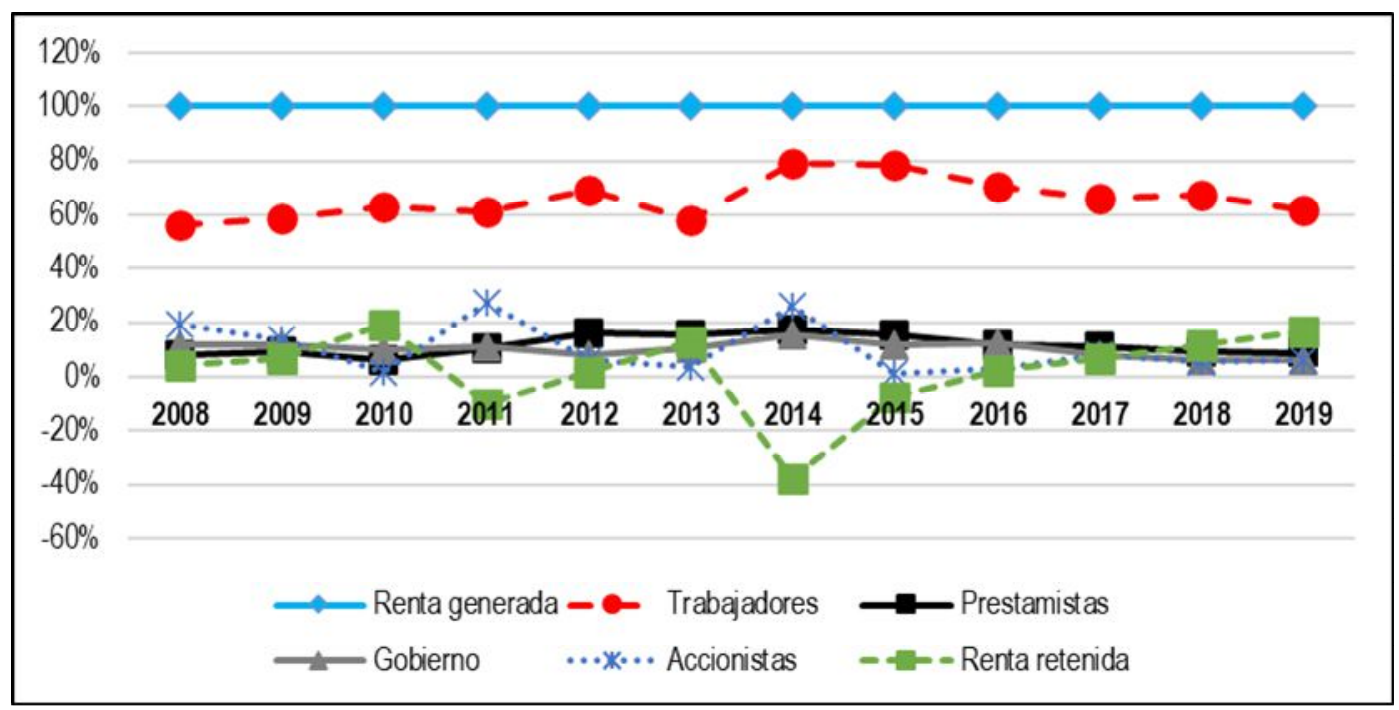

Fuente: Elaboración propia.

Déniz Mayor, J. J., Arteaga Arzola, L. M., y Manrique de Lara Peñate, $C$.
Vol. 7, núm. 19 / enero - abril del 2022 DOI: https://doi.org/10.36791/tcg.v7i19.135 


\section{Figura 6}

Distribución de rentas generadas en el sector de alojamiento, enfoque neto (porcentaje)

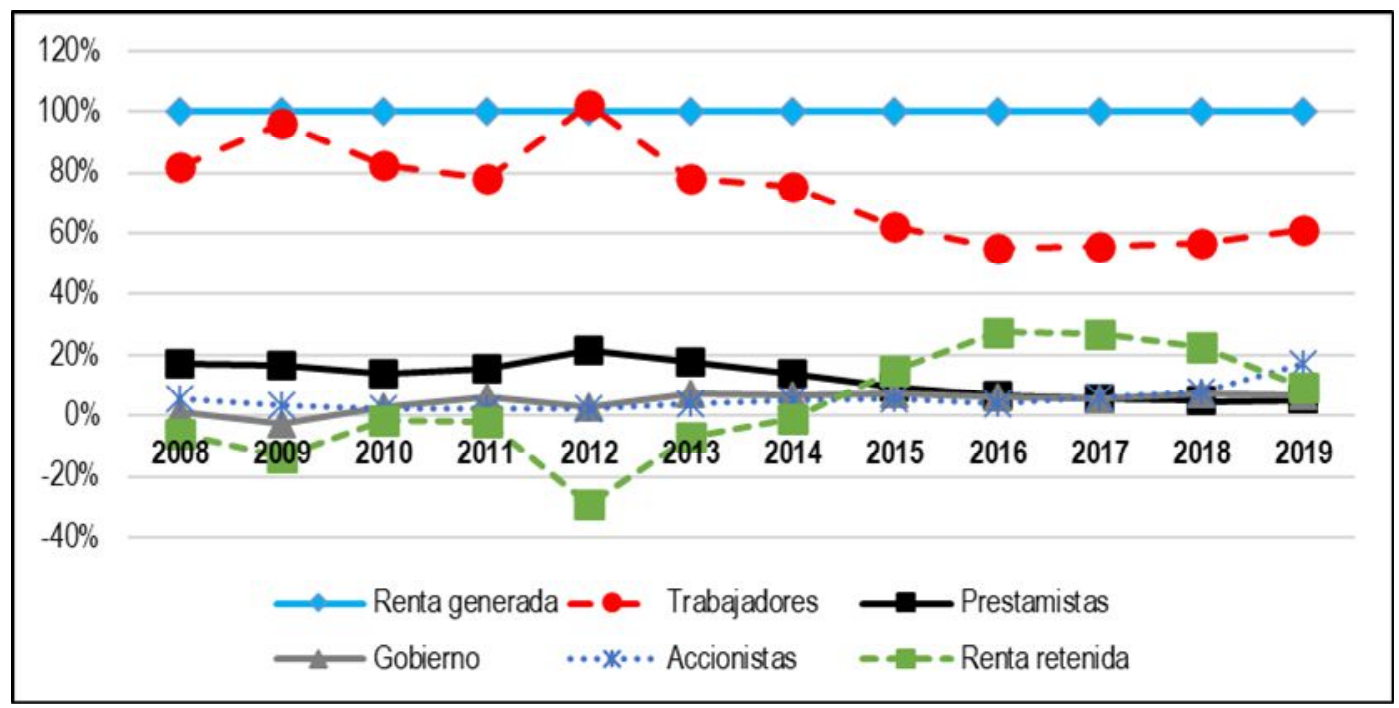

Fuente: Elaboración propia.

Dado el peso relativo de las rentas del trabajo en la distribución de las rentas generadas, parece oportuno realizar una comparativa en los tres sectores, observándose en la Figura 7 cómo en el año 2012 se produce la mayor participación de los trabajadores, tanto en el sector de la automoción como en el del alojamiento, al absorber incluso más del 100\% de las rentas generadas. Sin embargo, a partir de 2013 se produce una disminución paulatina, que se irá traduciendo en una convergencia de los tres sectores.
Así, en 2019 la automoción y el alojamiento hotelero se sitúan en cifras inferiores a las de 2008 (77\% frente al $93 \%$, en el primer caso, y $61 \%$ frente a $82 \%$ en el segundo caso). Obsérvese que en el sector de la construcción la participación de las rentas del trabajo acaba siendo mayor al final del periodo de análisis que al inicio del mismo (62\% frente al 56\%), para la muestra de empresas considerada, si bien es observable su declive desde 2015. 


\section{Figura 7}

Importancia relativa de las rentas del trabajo en los tres sectores, enfoque neto (porcentaje)

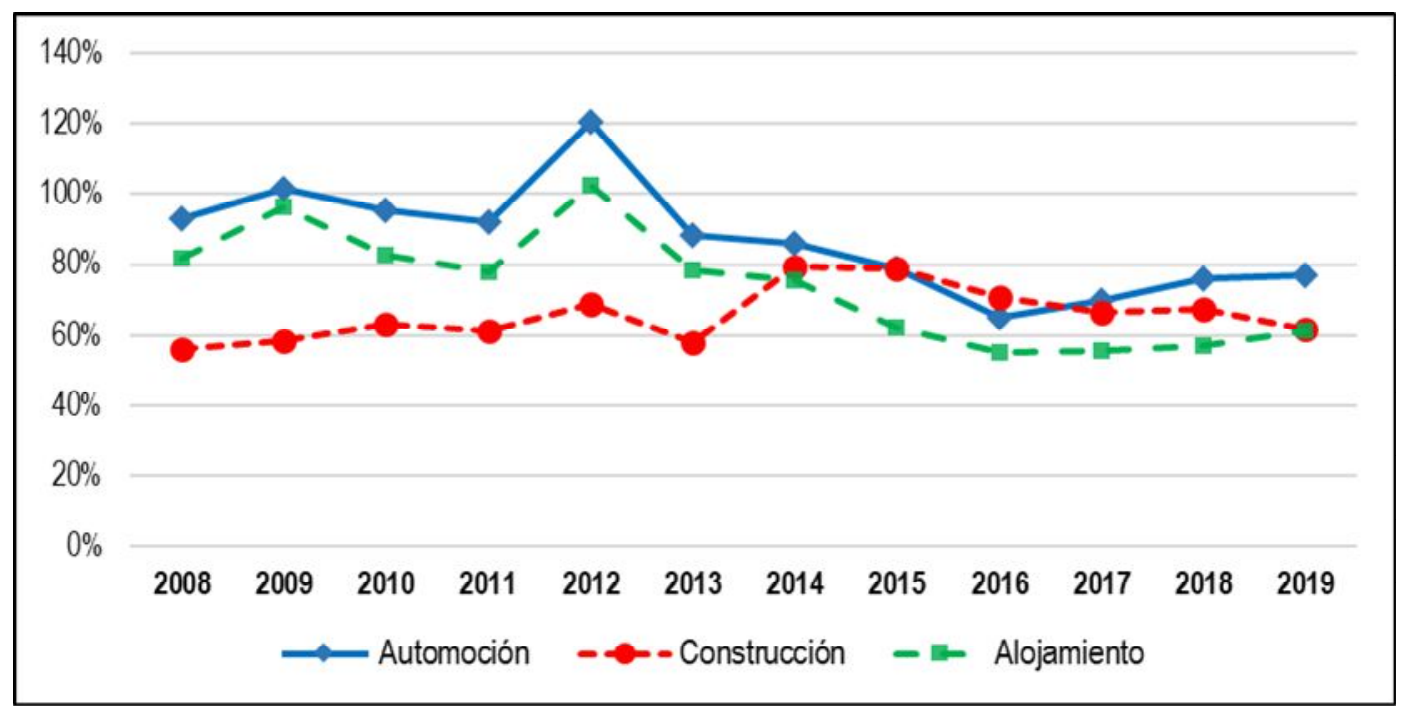

Fuente: Elaboración propia.

$\mathrm{Si}$, en términos porcentuales, se comparan las rentas retenidas en las empresas que conforman los tres sectores, éstas habrían estado sacrificando sus propias rentas para atender a los restantes partícipes.

Como se expone en la Figura 8, es a partir de 2015, tras diferentes vaivenes, cuando comienzan a remontar, si bien es el sector de la construcción el que manifiesta una tendencia creciente a largo plazo. Tras los vaivenes experimentados hasta 2013, la automoción y el alojamiento hotelero comienzan a despegar a partir de 2015, llegando a alcanzar porcentajes de rentas retenidas del $18 \%$ y el $27 \%$ respectivamente en 2016 , si bien a partir de este año, el ritmo de retención de rentas disminuye. Nótese que estos incrementos parecen coincidir con la reducción en la participación en las rentas experimentadas por los trabajadores.
Déniz Mayor, J. J., Arteaga Arzola, L. M., y Manrique de Lara Peñate, C.
Vol. 7, núm. 19 / enero - abril del 2022 DOI: https://doi.org/10.36791/tcg.v7i19.135 


\section{Figura 8}

Importancia relativa de las rentas retenidas, enfoque neto (porcentaje)

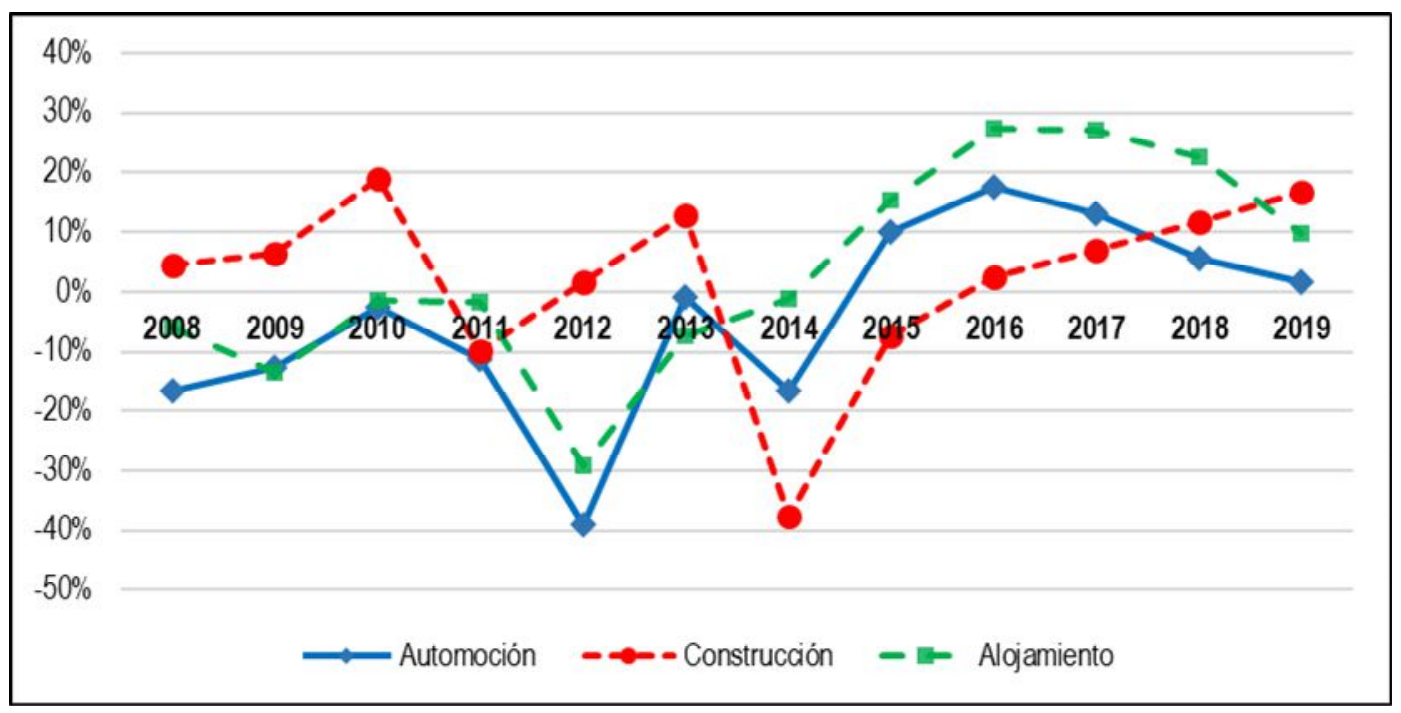

Fuente: Elaboración propia.

Un último apunte cabe hacer en torno a la importancia relativa de la amortización con respecto a las rentas generadas, reflejada en la Figura 9. Como era de esperar, el sector de automoción se caracteriza por el mayor peso de esta partida, seguido del alojamiento hotelero y por último de la construcción, con una tendencia decreciente en los dos primeros casos y una leve alza en el tercero. 


\section{Figura 9}

Importancia relativa de la amortización, enfoque neto (porcentaje)

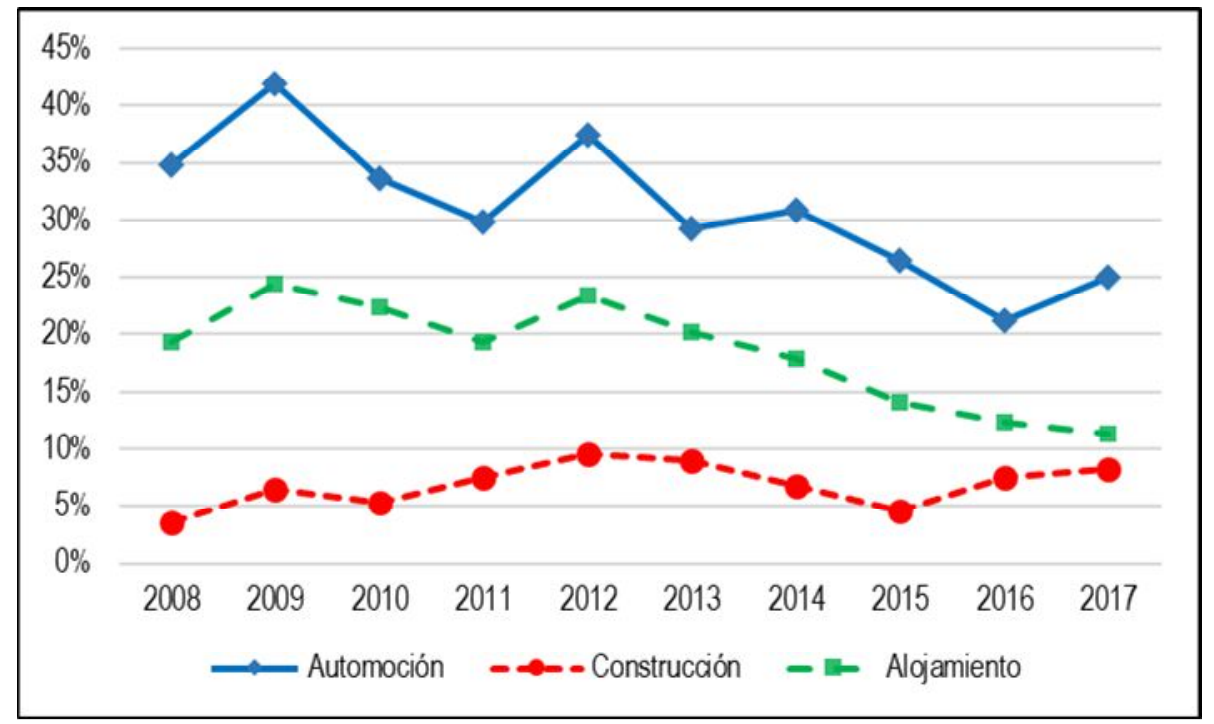

Fuente: Elaboración propia.

\section{Principales conclusiones}

En los últimos tiempos se ha observado una revitalización del EVA/ERGD, bajo nuevos ropajes, gracias a la GRI 201 (2016) que incluye un estado que muestra el valor económico directo generado y distribuido. Si bien no es exactamente igual, en la fase de reparto, al EVA/ERGD tradicional, pues su base de cálculo no es la renta sino los ingresos ordinarios y extraordinarios (con lo que hace visible a los proveedores de bienes y servicios como un grupo de interés más) representa un intento por mostrar quiénes son los colectivos beneficiarios de la actividad desarrollada por la empresa. Aunque el esfuerzo realizado en el seno de la GRI debe ser tenido en consideración, algunos aspectos deben ser objeto de reflexión, como la opcionalidad entre un modelo de presentación basado en el principio de devengo y otro sustentado en el principio de caja; la no distinción y separación entre propietarios y prestamistas como destinatarios de rentas, o la discusión sobre si la sociedad en general debe ser considerada como un destinatario de rentas o un beneficiario filantrópico.

Es de esperar que se refuerce la presentación de modelos de informes basados en la filosofía del EVA con la implantación de la Directiva 2014/95/UE del Parlamento Europeo y del Consejo por la que se modifica la Directiva 2013/34/UE en lo que respecta a la divulgación de información no financiera $e$ información sobre diversidad por parte de determinadas grandes empresas y determinados grupos, ${ }^{1} \mathrm{y}$ la

\footnotetext{
${ }^{1}$ Esta directiva, no propone un tipo de estado financiero específico, aunque en ella se declare como objetivo mostrar con mayor exactitud e información el valor que la entidad crea para la sociedad y el medio ambiente, entre otros, dentro de la Estrategia de la Unión Europea sobre responsabilidad social de las empresas (Comunicación de la Comisión de 25 de octubre de 2011).
} de Lara Peñate, $C$. 
Directiva (UE) 2017/828 del Parlamento Europeo y del Consejo, de 17 de mayo de 2017, por la que se modifica la Directiva 2007/36/CE en lo que respecta al fomento de la implicación a largo plazo de los accionistas.

Asimismo, en el presente trabajo se ha podido constatar que la estimación del valor añadido / renta generada de una empresa y su distribución entre los grupos de interés relevantes es relativamente fácil si se dispone de los datos contenidos en la Cuenta de pérdidas y ganancias y el Estado de cambios en el patrimonio neto. Que ello sea factible, sin necesidad de realizar ningún tipo de ajuste contable especial, hace que quepa cuestionarse la necesidad de diseñar un estado contable específico, salvo que en el mismo se aporte información adicional como la distribución de rentas salariales por categorías y género, o el reparto por zonas geográficas relevantes.

Cuestiones diferentes al mero cómputo de los datos son las relativas a los criterios contables a adoptar para determinar la base de reparto (valor bruto versus valor neto), la decisión en torno a si se sigue el principio de devengo o el de caja, o si, por ejemplo, las transferencias al gobierno deben mostrarse netas de subvenciones (en el Apéndice B se incluyen varias reflexiones al respecto); asuntos que, en definitiva, afectan al requisito de comparabilidad de la información financiera.

También está el aspecto quizás más importante y es de la relevancia de la información sobre el valor añadido ¿para qué y para quién debería ser relevante?

Evidentemente, bajo la perspectiva de la confrontación entre trabajo y capital, los EVA/ERGD no parecen ser útiles para la negociación colectiva si las rentas transferidas al personal no se presentan en términos desagregados por escala jerárquica, número de empleados y género, y quedan ocultas en ellas las retribuciones de la alta dirección y el consejo de administración. Como también queda oculto el creciente fenómeno de la "uberización”, que ha venido a superar el marco tradicional de relaciones laborales, basado en la negociación colectiva y el contrapoder sindical, para sustituirlo por meros acuerdos mercantiles, legitimadores de la figura del "falso autónomo" y de una flexibilidad contractual en la que supuestamente todos ganan y nadie pierde. También, y gracias a los avances en la robotización y la inteligencia artificial, es de esperar que el peso específico de los trabajadores (léase como distribución de rentas al factor trabajo) sea cada vez menor, en favor de los gastos por amortización (léase imputación al valor añadido).

Asimismo, no debe olvidarse que las rentas generadas en favor de los propietarios no están conformadas única y exclusivamente por los dividendos percibidos: hay que considerar las rentas por mera tenencia gracias a las plusvalías generadas y no contabilizadas, así como las rentas retenidas en la propia sociedad, que llegado el caso pueden ser transferidas a los socios, gracias al reparto de reservas voluntarias y otros fondos propios de libre disposición. 


\section{Apéndice A. Tablas de datos}

\section{Tabla A1}

Estadística descriptiva básica (miles de euros)

\begin{tabular}{|l|r|r|r|r|}
\hline Automoción (n=180) & \multicolumn{1}{|c|}{ Total } & \multicolumn{1}{c|}{ Media } & \multicolumn{1}{c|}{ Mediana } & Percentil 75 \\
\hline Activo 2008 & 18.483 .429 & 102.686 & 21.518 & 48.704 \\
\hline Activo 2012 & 17.560 .868 & 97.560 & 18.229 & 48.919 \\
\hline Activo 2019 & 22.514 .156 & 125.079 & 27.207 & 60.689 \\
\hline Patrimonio neto 2008 & 5.975 .424 & 33.197 & 6.701 & 16.768 \\
\hline Patrimonio neto 2012 & 5.291 .767 & 29.399 & 6.821 & 17.783 \\
\hline Patrimonio neto 2019 & 7.294 .781 & 40.527 & 10.201 & 26.257 \\
\hline Cifra neta de negocios 2008 & 33.725 .230 & 187.362 & 31.896 & 78.557 \\
\hline Cifra neta de negocios 2012 & 29.361 .021 & 163.117 & 27.472 & 60.345 \\
\hline Cifra neta de negocios 2019 & 43.400 .561 & 241.114 & 34.611 & 78.263 \\
\hline Resultado 2008 & -56.787 & -315 & 330 & 1.375 \\
\hline Resultado 2012 & -725.016 & -4.028 & 249 & 1.349 \\
\hline Resultado 2019 & 748.551 & 4.159 & 1.014 & 3.083 \\
\hline Construcción (n=183) & Total & Media & Mediana & Percentil 75 \\
\hline Activo 2008 & 23.327 .433 & 127.472 & 16.457 & 58.775 \\
\hline Activo 2012 & 21.043 .468 & 114.992 & 14.259 & 48.477 \\
\hline Activo 2019 & 16.771 .428 & 91.647 & 21.779 & 48.439 \\
\hline Patrimonio neto 2008 & 4.999 .818 & 27.321 & 3.859 & 15.598 \\
\hline Patrimonio neto 2012 & 5.521 .788 & 30.174 & 4.488 & 17.114 \\
\hline Patrimonio neto 2019 & 5.969 .871 & 32.622 & 6.131 & 18.373 \\
\hline Cifra neta de negocios 2008 & 16.331 .729 & 89.244 & 16.350 & 39.443 \\
\hline Cifra neta de negocios 2012 & 7.762 .715 & 42.419 & 11.361 & 20.974 \\
\hline Cifra neta de negocios 2019 & 9.781 .945 & 53.453 & 21.151 & 40.361 \\
\hline Resultado 2008 & 845.003 & 4.618 & 469 & 1.818 \\
\hline Resultado 2012 & 144.343 & 789 & 163 & 700 \\
\hline Resultado 2019 & 542.914 & 2.967 & 498 & 1.508 \\
\hline Alojamiento (n=265) & Total & Media & Mediana & Percentil 75 \\
\hline Activo 2008 & 14.060 .184 & 53.057 & 15.718 & 40.934 \\
\hline Activo 2012 & 15.770 .530 & 59.511 & 18.958 & 47.506 \\
\hline Activo 2019 & 20.918 .397 & 78.937 & 25.364 & 62.169 \\
\hline Patrimonio neto 2008 & 5.961 .260 & 22.495 & 5.651 & 18.136 \\
\hline Patrimonio neto 2012 & 6.583 .437 & 24.843 & 6.782 & 18.924 \\
\hline Patrimonio neto 2019 & 11.776 .811 & 44.441 & 12.900 & 34.187 \\
\hline Cifra neta de negocios 2008 & 3.884 .711 & 14.659 & 6.120 & 13.731 \\
\hline
\end{tabular}

Déniz Mayor, J. J., Arteaga Arzola, L. M., y Manrique de Lara Peñate, C. 


\section{Tabla A1}

Continuación...

\begin{tabular}{|l|r|r|r|r|}
\hline Alojamiento (n=265) & \multicolumn{1}{|c|}{ Total } & \multicolumn{1}{c|}{ Media } & \multicolumn{1}{c|}{ Mediana } & \multicolumn{1}{c|}{ Percentil 75 } \\
\hline Cifra neta de negocios 2012 & 4.151 .628 & 15.667 & 6.985 & 14.089 \\
\hline Cifra neta de negocios 2019 & 6.450 .592 & 24.342 & 11.025 & 20.477 \\
\hline Resultado 2008 & -11.566 & -44 & 57 & 629 \\
\hline Resultado 2012 & -395.327 & -1.492 & 76 & 681 \\
\hline Resultado 2019 & \multicolumn{1}{|c|}{ Total } & Media & Mediana & Percentil 75 \\
\hline Total (n=628) & 55.871 .046 & 88.967 & 17.116 & 47.692 \\
\hline Activo 2008 & 54.374 .866 & 86.584 & 18.055 & 48.006 \\
\hline Activo 2012 & 60.203 .981 & 95.866 & 24.683 & 58.060 \\
\hline Activo 2019 & 16.936 .502 & 26.969 & 5.459 & 16.485 \\
\hline Patrimonio neto 2008 & 17.396 .992 & 27.702 & 6.150 & 17.706 \\
\hline Patrimonio neto 2012 & 25.041 .463 & 39.875 & 9.179 & 26.160 \\
\hline Patrimonio neto 2019 & 53.941 .670 & 85.894 & 12.766 & 33.074 \\
\hline Cifra neta de negocios 2008 & 41.275 .364 & 65.725 & 10.865 & 25.661 \\
\hline Cifra neta de negocios 2012 & 59.633 .099 & 94.957 & 18.671 & 39.674 \\
\hline Cifra neta de negocios 2019 & 776.651 & 1.237 & 252 & 1.029 \\
\hline Resultado 2008 & -976.001 & -1.554 & 161 & 887 \\
\hline Resultado 2012 & 2.157 .024 & 3.435 & 830 & 2.713 \\
\hline Resultado 2019 & & & 3.017 \\
\hline
\end{tabular}

Fuente: Elaboración propia.

\section{Tabla A2}

Distribución de rentas generadas en el sector de automoción, enfoque neto (miles de euros)

\begin{tabular}{|l|r|r|r|r|r|r|}
\hline & \multicolumn{1}{l|}{$\begin{array}{l}\text { Renta } \\
\text { generada }\end{array}$} & Trabajadores & Prestamistas & Gobierno & \multicolumn{1}{l|}{ Accionistas } & $\begin{array}{l}\text { Renta } \\
\text { retenida }\end{array}$ \\
\hline $\mathbf{2 0 0 8}$ & 3.576 .315 & 3.330 .190 & 289.879 & 13.033 & 534.619 & -591.406 \\
\hline $\mathbf{2 0 0 9}$ & 3.048 .231 & 3.103 .437 & 178.982 & -139.550 & 289.467 & -384.105 \\
\hline $\mathbf{2 0 1 0}$ & 3.304 .161 & 3.157 .755 & 163.373 & -94.375 & 163.020 & -85.612 \\
\hline $\mathbf{2 0 1 1}$ & 3.402 .874 & 3.129 .182 & 163.819 & -20.398 & 517.005 & -386.734 \\
\hline $\mathbf{2 0 1 2}$ & 2.488 .990 & 3.003 .435 & 161.091 & 49.480 & 243.437 & -968.453 \\
\hline $\mathbf{2 0 1 3}$ & 3.500 .844 & 3.095 .604 & 113.615 & 124.036 & 200.610 & -33.021 \\
\hline $\mathbf{2 0 1 4}$ & 3.803 .582 & 3.270 .345 & 119.983 & 120.778 & 919.408 & -626.933 \\
\hline $\mathbf{2 0 1 5}$ & 4.380 .398 & 3.449 .428 & 97.695 & 132.285 & 261.308 & 439.682 \\
\hline $\mathbf{2 0 1 6}$ & 5.679 .855 & 3.688 .626 & 82.958 & 304.406 & 607.747 & 996.118 \\
\hline $\mathbf{2 0 1 7}$ & 5.350 .990 & 3.737 .582 & 75.708 & 177.849 & 656.959 & 702.891 \\
\hline $\mathbf{2 0 1 8}$ & 5.030 .996 & 3.820 .120 & 73.437 & 496.849 & 357.304 & 283.286 \\
\hline $\mathbf{2 0 1 9}$ & 5.116 .137 & 3.931 .747 & 69.094 & 366.745 & 660.208 & 88.342 \\
\hline
\end{tabular}

Fuente: Elaboración propia. 


\section{Tabla A3}

Distribución de rentas generadas en el sector de construcción, enfoque neto (miles de euros)

\begin{tabular}{|l|r|r|r|r|r|r|}
\hline & \multicolumn{1}{l|}{$\begin{array}{l}\text { Renta } \\
\text { generada }\end{array}$} & Trabajadores & Prestamistas & Gobierno & Accionistas & $\begin{array}{l}\text { Renta } \\
\text { retenida }\end{array}$ \\
\hline $\mathbf{2 0 0 8}$ & 3.561 .570 & 1.999 .347 & 288.969 & 428.251 & 685.530 & 159.473 \\
\hline $\mathbf{2 0 0 9}$ & 3.189 .367 & 1.871 .127 & 288.959 & 381.810 & 440.749 & 206.722 \\
\hline $\mathbf{2 0 1 0}$ & 2.726 .918 & 1.723 .071 & 167.497 & 268.118 & 48.551 & 519.680 \\
\hline $\mathbf{2 0 1 1}$ & 2.548 .092 & 1.556 .424 & 271.939 & 278.117 & 692.868 & -251.256 \\
\hline $\mathbf{2 0 1 2}$ & 1.931 .801 & 1.332 .695 & 304.576 & 150.187 & 113.328 & 31.015 \\
\hline $\mathbf{2 0 1 3}$ & 2.106 .914 & 1.218 .320 & 321.420 & 217.580 & 76.689 & 272.904 \\
\hline $\mathbf{2 0 1 4}$ & 1.460 .408 & 1.159 .194 & 248.280 & 226.193 & 377.290 & -550.548 \\
\hline $\mathbf{2 0 1 5}$ & 1.487 .799 & 1.170 .549 & 231.093 & 177.879 & 18.432 & -110.154 \\
\hline $\mathbf{2 0 1 6}$ & 1.748 .221 & 1.233 .236 & 201.417 & 215.507 & 53.880 & 44.182 \\
\hline $\mathbf{2 0 1 7}$ & 1.942 .471 & 1.288 .307 & 216.507 & 154.679 & 150.226 & 132.752 \\
\hline $\mathbf{2 0 1 8}$ & 1.988 .076 & 1.344 .793 & 182.009 & 120.843 & 105.534 & 234.898 \\
\hline $\mathbf{2 0 1 9}$ & 2.359 .970 & 1.460 .884 & 206.407 & 149.765 & 147.920 & 394.994 \\
\hline
\end{tabular}

Fuente: Elaboración propia.

\section{Tabla A4}

Distribución de rentas generadas en el sector de alojamiento, enfoque neto (miles de euros)

\begin{tabular}{|l|r|r|r|r|r|r|}
\hline & $\begin{array}{l}\text { Renta } \\
\text { generada }\end{array}$ & Trabajadores & Prestamistas & Gobierno & \multicolumn{1}{l|}{ Accionistas } & $\begin{array}{l}\text { Renta } \\
\text { retenida }\end{array}$ \\
\hline $\mathbf{2 0 0 8}$ & 1.673 .079 & 1.369 .867 & 290.285 & 24.493 & 90.072 & -101.637 \\
\hline $\mathbf{2 0 0 9}$ & 1.495 .419 & 1.437 .621 & 251.601 & -41.835 & 51.360 & -203.329 \\
\hline $\mathbf{2 0 1 0}$ & 1.769 .198 & 1.457 .672 & 249.182 & 51.710 & 37.184 & -26.550 \\
\hline $\mathbf{2 0 1 1}$ & 1.956 .019 & 1.525 .030 & 302.748 & 117.172 & 47.657 & -36.589 \\
\hline $\mathbf{2 0 1 2}$ & 1.482 .360 & 1.518 .947 & 317.581 & 41.159 & 36.399 & -431.726 \\
\hline $\mathbf{2 0 1 3}$ & 1.897 .559 & 1.486 .445 & 338.387 & 134.082 & 76.026 & -137.382 \\
\hline $\mathbf{2 0 1 4}$ & 2.009 .302 & 1.516 .306 & 280.012 & 136.603 & 98.629 & -22.247 \\
\hline $\mathbf{2 0 1 5}$ & 2.583 .962 & 1.602 .887 & 248.080 & 193.919 & 145.587 & 393.489 \\
\hline $\mathbf{2 0 1 6}$ & 3.116 .591 & 1.721 .239 & 207.538 & 200.017 & 132.462 & 855.336 \\
\hline $\mathbf{2 0 1 7}$ & 3.305 .221 & 1.831 .259 & 191.920 & 184.504 & 202.128 & 895.410 \\
\hline $\mathbf{2 0 1 8}$ & 3.290 .492 & 1.875 .889 & 167.390 & 244.637 & 261.467 & 741.109 \\
\hline $\mathbf{2 0 1 9}$ & 3.214 .257 & 1.969 .060 & 166.691 & 212.946 & 554.060 & 311.500 \\
\hline
\end{tabular}

Fuente: Elaboración propia.

Déniz Mayor, J. J., Arteaga Arzola, L. M., y Manrique de Lara Peñate, $C$.
Vol. 7, núm. 19 / enero - abril del 2022 DOI: https://doi.org/10.36791/tcg.v7i19.135

Pp. 107-149 


\section{Tabla A5}

Impuestos vs Impuestos netos (miles de euros)

\begin{tabular}{|l|r|r|r|r|r|r|r|r|r|}
\hline & \multicolumn{4}{|l|}{ Automoción } & \multicolumn{2}{l|}{ Construcción } & \multicolumn{2}{|l|}{ Alojamiento } \\
\hline & $\begin{array}{c}\text { Impues- } \\
\text { tos }\end{array}$ & $\begin{array}{c}\text { Subvencio- } \\
\text { nes }\end{array}$ & $\begin{array}{c}\text { Impues- } \\
\text { tos netos }\end{array}$ & $\begin{array}{c}\text { Impues- } \\
\text { tos }\end{array}$ & $\begin{array}{c}\text { Subvencio- } \\
\text { nes }\end{array}$ & $\begin{array}{l}\text { Impues- } \\
\text { tos netos }\end{array}$ & $\begin{array}{c}\text { Impues- } \\
\text { tos }\end{array}$ & $\begin{array}{c}\text { Subvencio- } \\
\text { nes }\end{array}$ & $\begin{array}{l}\text { Impues- } \\
\text { tos netos }\end{array}$ \\
\hline $\mathbf{2 0 0 8}$ & 13.033 & 77.145 & -64.113 & 428.251 & 34.249 & 394.002 & 24.493 & 36.732 & -12.239 \\
\hline $\mathbf{2 0 0 9}$ & -139.550 & 142.970 & -282.520 & 381.810 & 27.322 & 354.488 & -41.835 & 46.561 & -88.396 \\
\hline $\mathbf{2 0 1 0}$ & -94.375 & 116.830 & -211.206 & 268.118 & 24.752 & 243.366 & 51.710 & 69.144 & -17.433 \\
\hline $\mathbf{2 0 1 1}$ & -20.398 & 86.315 & -106.713 & 278.117 & 30.575 & 247.542 & 117.172 & 39.564 & 77.608 \\
\hline $\mathbf{2 0 1 2}$ & 49.480 & 55.073 & -5.592 & 150.187 & 18.801 & 131.386 & 41.159 & 32.967 & 8.192 \\
\hline $\mathbf{2 0 1 3}$ & 124.036 & 45.435 & 78.602 & 217.580 & 14.391 & 203.190 & 134.082 & 29.592 & 104.489 \\
\hline $\mathbf{2 0 1 4}$ & 120.778 & 53.805 & 66.973 & 226.193 & 28.271 & 197.922 & 136.603 & 24.526 & 112.077 \\
\hline $\mathbf{2 0 1 5}$ & 132.285 & 55.056 & 77.229 & 177.879 & 69.570 & 108.308 & 193.919 & 26.918 & 167.001 \\
\hline $\mathbf{2 0 1 6}$ & 304.406 & 42.071 & 262.335 & 215.507 & 36.641 & 178.866 & 200.017 & 25.091 & 174.926 \\
\hline $\mathbf{2 0 1 7}$ & 177.849 & 40.979 & 136.870 & 154.679 & 58.948 & 95.731 & 184.504 & 22.252 & 162.251 \\
\hline $\mathbf{2 0 1 8}$ & 496.849 & 36.790 & 460.059 & 120.843 & 52.059 & 68.784 & 244.637 & 34.324 & 210.313 \\
\hline $\mathbf{2 0 1 9}$ & 366.745 & 49.113 & 317.631 & 149.765 & 61.540 & 88.225 & 212.946 & 24.074 & 188.872 \\
\hline
\end{tabular}

Fuente: Elaboración propia.

\section{Tabla A6}

La amortización en los sectores analizados (miles de euros)

\begin{tabular}{|r|r|r|r|}
\hline & Automoción & Construcción & Alojamiento \\
\hline $\mathbf{2 0 0 8}$ & 1.381 .392 & 118.726 & 334.725 \\
\hline $\mathbf{2 0 0 9}$ & 1.298 .797 & 129.996 & 392.689 \\
\hline $\mathbf{2 0 1 0}$ & 1.138 .085 & 126.310 & 407.618 \\
\hline $\mathbf{2 0 1 1}$ & 1.027 .818 & 125.043 & 393.455 \\
\hline $\mathbf{2 0 1 2}$ & 935.234 & 109.543 & 385.691 \\
\hline $\mathbf{2 0 1 3}$ & 1.020 .007 & 97.863 & 396.973 \\
\hline $\mathbf{2 0 1 4}$ & 1.159 .596 & 85.466 & 385.590 \\
\hline $\mathbf{2 0 1 5}$ & 1.109 .209 & 73.080 & 382.548 \\
\hline $\mathbf{2 0 1 6}$ & 1.090 .625 & 77.188 & 391.398 \\
\hline $\mathbf{2 0 1 7}$ & 1.252 .554 & 79.030 & 405.318 \\
\hline $\mathbf{2 0 1 8}$ & 1.342 .600 & 76.667 & 418.117 \\
\hline $\mathbf{2 0 1 9}$ & 1.408 .132 & 78.484 & 454.220 \\
\hline
\end{tabular}

Fuente: Elaboración propia. 


\section{Apéndice B. Comentarios sobre determinadas partidas contables del estado de rentas generadas y distribuidas}

En los siguientes apartados se presentan posibles criterios a adoptar para definir y calcular determinadas magnitudes representativas de las rentas distribuidas, realizando una recapitulación de lo expuesto y estudiando detenidamente las dificultades y complejidades asociadas. Dada la extensión del presente trabajo, se ha optado por no incluir las partidas relacionadas con la generación de rentas, excepto en aquellos casos en los que se considere imprescindible, en virtud del enfoque de estimación adoptado (bruto vs neto, compras vs coste de la venta, o tributos vs tributos netos de subvenciones).

\section{Ingresos y gastos asociados a la generación de renta}

Variaciones de existencias de productos terminados, semiterminados y trabajos en curso. Si se sigue el enfoque del coste de las ventas y en concordancia con Flores (2005, p. 64), pueden formar parte del valor añadido generado, como componente del ingreso y valoradas a coste de producción o adquisición, las diferencias entre los saldos iniciales y finales de los inventarios de productos terminados, semiterminados, subproductos y trabajos en curso, es decir, la variación de existencias de estos activos, opinión que es compartida por Pastor et. al (2011) y su modelo basado en la producción.

Subvenciones. Una corriente de autores considera que cualquier tipo de ayuda de Estado recibida por la entidad debe entenderse como una menor distribución del valor añadido generado a este agente (véase Reichmann y Lange, 1980, Haller y van Staden, 2014). Sin embargo, otros como Gallizo (1991, p. 78) matizan que las subvenciones a la explotación deberán integrarse en el valor añadido solo en aquella fracción que el subsidio toma parte en el precio final pagado por el cliente, tratándolas como ingresos derivados de la actividad de explotación y, por tanto, partícipes de la generación de valor. Este autor dice que no formarán parte de este último cualquier otra subvención con otra finalidad en el ciclo de explotación ni las subvenciones al capital. Por su parte, Flores (2005, p. 62) considera las subvenciones a la explotación incorporables en su totalidad al valor añadido, no siguiendo el mismo criterio para el resto de subsidios. Asimismo, cabe señalar el posicionamiento del Banco de España (2015, p. 106) consistente en incluir todo tipo de subvención como ingreso computable, haciendo una excepción con las de capital transferidas al resultado, que serán incorporadas neteando (restando) la amortización del inmovilizado al que financian (esto sería en el caso del valor añadido bruto, pues en el valor añadido neto se tendrían en cuenta al descontar la dotación a la amortización en su conjunto).

Sin perjuicio de otras consideraciones más acertadas en contrario, no sería descartable considerar las subvenciones recibidas como menor importe de la renta distribuida en favor del gobierno y no como un mayor ingreso imputable. Este posicionamiento se basa en la idea de que tales ingresos no son creación de valor por parte de la empresa (salvo en el caso de las subvenciones al precio de venta a favor del consumidor) sino una transferencia de renta desde el sector público ${ }^{1}$. Así pues, al abordar la distribución de la renta generada, esa ayuda de Estado debería restarse del reparto a dicho agente, mostrando el signo del saldo resultante la efectiva relación existente entre la entidad y los poderes públicos, un aspecto considerado a veces conflictivo a la

\footnotetext{
${ }^{1}$ Dichas partidas se presentan en los estados contables agregadas con las donaciones de particulares y los legados. En los casos en los que sea factible diferenciar las rentas que tengan estas características deberán realizarse los oportunos ajustes al objeto de una correcta clasificación.
}

Déniz Mayor, J. J., Arteaga Arzola, L. M., y Manrique de Lara Peñate, C. 
hora de rendir cuentas ante la sociedad en general y evaluar el papel que desempeñan las ayudas públicas (Gracia, 2013).

Procede hacer una matización en lo que respecta a las subvenciones recibidas para financiar gastos específicos, adquirir activos (sean corrientes o de capital), cancelar pasivos o compensar déficits futuros. De acuerdo con la regulación contable vigente, aunque dichas partidas, cumpliendo los requisitos correspondientes, constituyen un ingreso, su imputación no se realiza directamente al resultado del ejercicio sino al patrimonio neto, figurando sus movimientos no en la Cuenta de pérdidas y ganancias sino en el Estado de ingresos y gastos reconocidos. Sólo a medida que se vayan cumpliendo las condiciones establecidas al efecto se irá produciendo su transferencia al resultado. Dado que en los modelos usuales de estimación del valor añadido y las rentas generadas solo se consideran los ingresos y gastos incluidos en la Cuenta de pérdidas y ganancias, este hecho constituye una limitación al análisis que podría obligar a ampliar el universo de ingresos computables para incluir no solo los reflejados en la Cuenta de pérdidas y ganancias sino además los recogidos en el
Estado de ingresos y gastos reconocidos. En tal caso y para evitar problemas de doble contabilización, los ingresos transferidos citados anteriormente deberían ser eliminados del cómputo ${ }^{1}$.

Aun así, todavía quedaría oculta la ayuda indirecta del gobierno, mediante, por ejemplo, la construcción de vías de dominio público para facilitar el acceso a las instalaciones de la entidad, la facilitación de suelos a bajo coste o gratuitos, la exención del pago de impuestos sobre la propiedad, etc..., ventajas todas ellas que, debido a su consideración de externalidades positivas (en este caso, de la Administración) en favor de la empresa, no son susceptibles de reconocimiento contable.

Amortización del inmovilizado intangible, material e inmobiliario $^{2}$. En lo que respecta a esta partida, hay que hacer referencia, en primer lugar, al debate en torno a qué modelo, si el basado en el valor añadido bruto o en el valor añadido neto, debe ser el prevalente.

Desde la perspectiva del valor bruto, su determinación lleva consigo el problema de arrastrar a lo largo del proceso de cálculo el trato que se le da a la amortización

\footnotetext{
${ }^{1}$ Bajo el modelo contable español este proceso se realiza de forma automática al formular el Estado de ingresos y gastos reconocidos (EIGR), pues al registrar la transferencia de dichos ingresos al resultado del ejercicio, el saldo del EIGR se minora mientras que el de la Cuenta de pérdidas y ganancias aumenta, en ambos casos por la misma cuantía. No obstante, es pertinente hacer algunas matizaciones en torno al proceso de cálculo de la partida "Subvenciones de explotación recibidas en el ejercicio". En la partida "A.5.b). Subvenciones de explotación incorporadas al resultado del ejercicio", del modelo normal de la Cuenta de pérdidas y ganancias, se incluyen tanto las recibidas e imputadas durante el ejercicio como las transferidas desde el EIGR, a través de su partida "VIII. Subvenciones, donaciones y legados recibidos" (transferencias a la Cuenta de pérdidas y ganancias). El inconveniente es que esta partida también incluye las transferencias realizadas a la partida "A.9. Imputación de subvenciones de inmovilizado no financiero y otras" de la citada Cuenta de pérdidas y ganancias.

De no realizar ningún ajuste, se estaría registrando en la partida A.5.b) como ingreso del ejercicio un ingreso que fue previamente registrado en el EIGR cuando se obtuvo la subvención, dando origen a un problema de doble contabilización, desde el punto de vista del cálculo de las rentas generadas. Realizando una sencilla operación aritmética (considerando las partidas en valores absolutos (positivos): "Subvenciones de explotación recibidas en el ejercicio" = "A.5.b). Subvenciones de explotación incorporadas al resultado del ejercicio” - "VIII. Subvenciones, donaciones y legados recibidos" + “A.9. Imputación de subvenciones de inmovilizado no financiero y otras”) se elimina la parte incorporada desde el EIGR, de forma que la partida de Subvenciones de explotación registre solo las efectivamente recibidas durante el ejercicio.

${ }^{2}$ Si se compara con el SEC 2010, la amortización se asimila al concepto de consumo de capital fijo, pero con ciertas matizaciones. Así, frente a las diferentes alternativas valorativas recopiladas en la literatura sobre Contabilidad Financiera, la norma establece que debe calcularse "según el método de la amortización lineal, mediante el cual el valor de los activos fijos se amortiza a una tasa constante durante toda la vida útil del bien" (párr. 3.143) y que "en algunos casos, si un activo fijo pierde su eficacia, se utiliza el método de la amortización geométrica” (párr. 3.144)
} 
y el método usado para su obtención, muchas veces con una base muy subjetiva al estar sustentada en estimaciones. En este aspecto, Gallizo (1990) sostiene que tales dotaciones son constitutivas de valor añadido, basándose en la concordancia que este planteamiento tiene con los cálculos macroeconómicos, donde el valor añadido se obtiene bruto de amortización. A su vez, cuestiona la subjetividad inherente a la estimación de la depreciación, entendiendo que la amortización deba tratarse como parte de la autofinanciación de la empresa, mostrándose en dicho caso junto con los beneficios retenidos para la propia entidad, como uno de los destinos últimos en la distribución del valor añadido ${ }^{1}$. Este posicionamiento elimina la subjetividad ya que, según Azcarate y Fernández (2013), al no formar parte de la generación del valor añadido, solo tendrá repercusión en la diferenciación que se haga entre fondos, bien sea de financiación de mantenimiento (amortización propiamente dicha) o de crecimiento (renovación y mejora), afectando únicamente en ambos casos al mismo partícipe, la propia empresa.

Bajo el enfoque del valor neto, las amortizaciones, provisiones de pasivo (salvo las de personal y para la Hacienda pública) y deterioros de valor son considerados un coste para la creación de riqueza (a través de la disminución del valor de activo en el caso de las amortizaciones y los deterioros de valor y el afloramiento de un pasivo a través de las provisiones) y, por tanto, minorarían la cifra de negocios. Riechmann y Lange (1981) argumentan que dichos conceptos están relacionados con operaciones comerciales de intercambio de bienes y prestaciones de servicios. Así, la amortización representa una parte de la salida de recursos que se emplearon para adquirir un inmovilizado y en proporción a su vida útil en la empresa; las provisiones suponen el reconocimiento de la probable futura salida de recursos mientras que el deterioro, de la probable minoración de la entrada de recursos que se producirá como contraprestación a la baja/uso en la empresa de los activos que se estiman se están deteriorando. Este último posicionamiento sigue estrechamente los principios contables, especialmente los principios de devengo y prudencia. Pastor et al. (2011) también optan por el valor neto, ya que entienden que las amortizaciones no producen un movimiento de fondos, al tratarse de la expresión económica de la depreciación de activos por su uso en el proceso productivo y, por tanto, un componente del coste de las ventas.

Morley (1979, pp. 626-628) centra su apoyo al enfoque neto en los siguientes aspectos: la empresa puede distribuir entre los partícipes el $100 \%$ del valor añadido neto, pero no puede distribuir el 100\% del valor añadido bruto porque parte de ese valor ya está consumido en la propia empresa. Por lo tanto, el valor añadido neto puede ser una base más justa para el cálculo de, por ejemplo, los bonos de productividad.

Un argumento adicional es que, si la empresa registra la aplicación de materias primas y otros

\footnotetext{
${ }^{1}$ Este es el enfoque que subyace bajo la noción tradicional de Fondo de amortización, considerada como una partida integrante de los fondos propios de la empresa (si bien desde el punto de vista de la regulación española figura en el activo del balance como un menor valor de los elementos representados). Desde tal perspectiva, que conforma el denominado significado financiero de la amortización económica (Fernández, 1983), dicho fondo es creado con el objeto de compensar deterioros de valor o depreciaciones sufridas por los elementos patrimoniales. El importe de este fondo crecerá, ejercicio a ejercicio, en igual cuantía que la dotación, por lo que al final de la vida útil económica del bien amortizable la entidad podrá efectuar su reposición con los importes materializados en el activo equivalentes al montante de dicho fondo.
}

Déniz Mayor, J. J., Arteaga Arzola, L. M., y Manrique de Lara Peñate, $C$. 
aprovisionamientos como un consumo intermedio, ¿no debería hacerse lo propio (como se hace con la amortización) con otros activos no monetarios, como los edificios o la maquinaria, con independencia de cuál sea el plazo durante el cual contribuyan a la generación de ingresos?

\section{Distribución de las rentas}

Los grupos de interés o participes en el reparto son aquellos entes que, de una manera u otra, han contribuido a la formación de la renta y, por tanto, esperan recibir una porción en la distribución de ésta como contraprestación. Entre los grupos más relevantes, destacan:

Empleados. Son las personas de que dispone la entidad para realizar su actividad económica. Dentro de esta categoría, cabría distinguir, en una primera aproximación, entre los trabajadores manuales u operativos, que representarían el grueso de los asalariados, y los directivos y administradores. Al entenderse que la contribución y remuneración de cada uno de estos grupos es distinta (mayores salarios para los directivos versus mayores jornadas laborales de los trabajadores de base) si se mostrasen agregados se distorsionaría la realidad de cada uno de estos grupos, por lo que es recomendable que, al igual que proponen algunos autores ${ }^{1}$, se presenten los datos relativos a cada grupo por separado.

Aparte de las retribuciones percibidas vía nómina, se deben incluir las cuotas a la seguridad social aportadas por la empresa (aunque no sean una renta recibida directamente por el trabajador, si lo es de forma indirecta) (GRI 201, 2016), las dotaciones a provisiones para la jubilación o prestaciones por incapacidad, así como otros gastos sociales, tales como subvenciones a economatos y comedores, becas para el estudio, o primas por contratos de seguros de vida, accidentes, enfermedad, etc. entre otros.

Por el contrario, deben excluirse los gastos de formación recibidos, siempre y cuando dicha formación sea impartida por personal externo de la entidad. Este posicionamiento coincide con el de la GRI 201 (2016), y está basado en que dicho esfuerzo formativo de la entidad repercutirá en una mayor calidad del producto o servicio que ofrezca la entidad, siendo el empleado el medio para conseguir dicho objetivo y no el destinatario final del mismo. Tampoco computaría el reembolso de los gastos de viaje, de desplazamiento, de mudanza y de representación en los que incurren los asalariados en el ejercicio de sus funciones que sí formarían parte de los consumos intermedios y no de las rentas distribuidas, por entenderse que son necesarios para la producción (SEC 2010 párr. 3.89.h). Así como las adquisiciones realizadas por los trabajadores y que son reembolsados por el empleador, en virtud de una obligación contractual (SEC 2010, párr. 3.89.g), como herramientas o equipos de seguridad.

De acuerdo con los pronunciamientos en materia de igualdad de género, deberán diferenciarse las cuantías asignadas a hombres y mujeres por separado.

Estado. Se debe aclarar que bajo la figura de "Estado" se incluyen todos los niveles de administración (en España: Administración General del Estado, Comunidades Autónomas, Cabildos Insulares, Ayuntamientos, Diputaciones, etc.). Como se ha indicado, algunos autores cuestionan que este sector económico se considere un destinatario de rentas a

\footnotetext{
${ }^{1}$ Véase, por ejemplo, Pong y Mitchell (2005, pp. 190-191) el debate sobre la visibilización de las retribuciones de los directivos y el problema del riesgo moral, bajo la perspectiva de la teoría de agencia.
} 
efectos del EVA/ERGD al no quedar suficientemente claro en qué consiste su contribución a la generación de las mismas en el seno de la empresa.

La transferencia de rentas desde la empresa se realiza en forma de impuestos, tanto directos como indirectos, tasas y contribuciones especiales. Sería conveniente tener en cuenta que muchos sectores económicos reciben subvenciones y otros tipos de ayudas, por lo que podría resultar sumamente ilustrativo que de la parte que la entidad aporta al Estado en forma de impuestos se le descontase la parte recibida como subvención, tal y como se comentó anteriormente ${ }^{1}$.

Un problema a considerar es el caso de los impuestos soportados no deducibles, pues al registrase como consumos intermedios, como mayor precio de adquisición, entonces no se conoce el peso real de la contribución de la empresa a las arcas públicas.

Proveedores de capital ajeno. Son terceros suministradores de fondos de naturaleza reintegrable a la empresa, en su mayoría, entidades financieras y proveedores de inmovilizado. Sus rentas provienen de los rendimientos obtenidos, vía intereses y asimilados, por la cesión de tales pasivos.

Flores (2005) sostiene que cuando los gastos financieros están relacionados con la gestión o descuento de papel comercial tienen la consideración de servicios adquiridos del exterior y por tanto constituyen una minoración del valor añadido y no una renta distribuida, como sucedería por ejemplo con los arrendamientos financieros. En este caso, y de acuerdo con el vigente Plan General de Contabilidad de 2007 siguiendo los pronunciamientos internacionales, dichas operaciones son consideradas como préstamos, entendiendo que las mensualidades a abonar estarían integradas por los reembolsos del capital y los intereses, conceptos estos últimos constitutivos de la distribución de las rentas generadas al capital ajeno. Con la excepción de los gastos antes descritos de carácter comercial, así como de los descuentos comerciales por pronto pago, la partida de gastos financieros constituye una renta distribuida a los aportantes de fondos ajenos, en concordancia con el SEC 2010 (párr. 4.42).

Mención aparte cabe realizar en torno los gastos por arrendamiento. Autores como Hernández (1997, p. 144) defienden su inclusión en el cómputo del valor añadido, siempre que la actividad principal de la entidad arrendadora sea ceder dichos bienes, en cambio, si no fuese ese el caso, se debería considerar como una aplicación de la renta generada por la empresa, en concordancia con la Contabilidad Nacional. En el Plan General de Contabilidad de 1990 esta partida ya aparecía excluida del cómputo del valor añadido por ser una renta transferida por la empresa a los propietarios de los activos utilizados por ella. No obstante, en el modelo SEC 2010 los arrendamientos operativos que no sean rentas de la propiedad son considerados consumos intermedios (párrs. 3.89, 4.41, 4.72), pues estas últimas forman parte de las denominadas rentas primarias. Se entiende por rentas de la propiedad las obtenidas cuando los propietarios de instrumentos financieros y recursos naturales los ponen a disposición de un tercero. El SEC 2010 (párr. 3.90 g) señala explícitamente que los pagos por licencias de explotación de recursos naturales que son tratados como arrendamientos no son consumos intermedios sino rentas de la propiedad. La Resolución

\footnotetext{
${ }^{1}$ En algunos EVA de los años 70 (ver el caso del informe de 1977 de ICI, estudiado por Morley, 1979, p. 626) las ayudas aparecen minorando los impuestos.
}

Déniz Mayor, J. J., Arteaga Arzola, L. M., y Manrique de Lara Peñate, C.
Vol. 7, núm. 19 / enero - abril del 2022 DOI: https://doi.org/10.36791/tcg.v7i19.135

Pp. 107-149 
Técnica FACPCE 36 argentina incluye los arrendamientos y otros pagos como royalties, derechos de autor, seguros y similares, como rentas a los proveedores de capital ajeno.

Propietarios. A diferencia del caso anterior, se trata de suministradores de fondos a la empresa a cambio de una participación en el capital social en calidad de socios o partícipes. Sus rentas provienen de los rendimientos obtenidos, vía dividendos y asimilados. Un caso singular de distribución a propietarios se encuentra en el pago de dividendos contra reservas. Dado que no se trata de rentas generadas en el ejercicio sino en periodos anteriores, se suscita la duda de si efectivamente se trata de una distribución de rentas o de una mera reasignación interna (dado que los fondos previamente transferidos a la "propia empresa", no dejan de ser rentas de los propietarios aparcadas transitoriamente en la compañía). Ello puede dar lugar a una discrepancia en la igualdad entre rentas generadas y rentas distribuidas, de la que debería informarse en el ERGD, distinguiendo qué parte de dividendos corresponde a cada ejercicio.

Sociedad. La contribución de la empresa a la sociedad en general se realiza participando directamente en la comunidad o su entorno, por ejemplo, mediante actos discrecionales y filantrópicos. Dado el creciente peso de las políticas de responsabilidad social corporativa, procede plantearse la conveniencia de reflejar las donaciones y contribuciones benéficas realizadas en favor de iniciativas y proyectos sociales, culturales y ambientales.

Se ha argumentado que la sociedad en general contribuye a la generación de rentas empresariales, no solo como consumidora directa de los productos o servicios ofertados por la entidad, sino indirectamente a través del flujo monetario entre clientes de la entidad y otras personas que no consumen (y que tal vez una donación por parte de la entidad pudo hacerla posible), por lo que una contribución a la sociedad en general, puede generar rentas en la entidad directa o indirectamente. No obstante, no deja de ser una cuestión controvertida, debiendo aclararse si este grupo es un destinatario de rentas en sentido estricto, o bien un beneficiario de la acción filantrópica corporativa.

Propia empresa. De las rentas generadas, los propietarios reservan una parte de las mismas para apoyar la continuidad de la actividad empresarial o bien distribuirlas como dividendos en ejercicios futuros. Dentro de esta categoría se encuentra la compensación de pérdidas de ejercicios anteriores o las dotaciones de reservas. Como ya se ha mencionado anteriormente, hay modelos como los basados en el enfoque bruto que incluyen en este apartado la dotación a la amortización, al entender que la entidad debe tener en cuenta el desgaste de estos elementos y reservar una parte para la renovación de dicho inmovilizado. El objetivo perseguido es doble: en primer lugar, no afectar al resto de grupos en la distribución, pues éste es un gasto específico de la entidad para su mantenimiento en el mercado. En segundo lugar, minorar el efecto de la subjetividad de estos gastos, debido a que, en caso de manipulación contable, el afectado siempre sería la propia entidad (Morley, 1979, p. 626), sobre todo cuando los incentivos salariales se vinculan al valor añadido (el trabajador puede temer que la inclusión de un coste subjetivo como la amortización incite a los directivos a manipular el valor añadido para reducir sus bonos). Por otra parte, otros modelos sostienen que la variación positiva en existencias y productos finales deba entenderse como una porción del valor ya distribuida durante el ejercicio y que la entidad ya ha realizado para el mantenimiento de su actividad. 


\section{Referencias}

Accounting Standards Steering Committee (ASSC). (1975). The Corporate Report. A discussion paper published for comment by the Accounting Standards Steering Committee. The Institute of Chartered Accountants in England and Wales (ICAEW). https://www.icaew.com//media/corporate/files/library/subjects/corporategovernance/corporate-report.ashx?la=en

Autorité des Normes Comptables. (2014). Règlement ANC No 2014-03 relatif au Plan Comptable Général. https://www.anc.gouv.fr/files/live/sites/anc/files/contri buted/ANC/1_Normes_fran\%C3\%A7aises/Reglements /Recueils/PCG_Janvier2019/PCG_2019.pdf

Alves, S. (2015). Implicación de las empresas multinacionales en la desigualdad global, ineficacia de la responsabilidad social corporativa y el papel de la contabilidad (tesis doctoral, Universidad de Zaragoza). http://zaguan.unizar.es/record/47868

Azcárate, F., y Fernández, M. (2013). El Estado de Valor Añadido: una propuesta alternativa para la diferenciación entre los posicionamientos Bruto y Neto. Revista Contable, 16, 40-51. http://aeca.es/old/actualidadnic/noticias88/040_articulo _valor_16.pdf

Bao, B. H., y Bao, D. H. (1998). Usefulness of value added and abnormal economic earnings: an empirical examination. Journal of Business \& Accounting, 25(1/2), 251-264. https://doi.org/10.1111/14685957.00186

Bagieńska A. (2016). Value added statement - a relevant instrument for integrated reporting. Financial Internet Quarterly "e-Finanse", 12(4), 92-104.

https://doi.org/10.1515/fiqf-2016-0011
Barea, J. (1986). El Plan General de Contabilidad Revisado: una aproximación al análisis económico de la empresa. Revista Española de Financiación y Contabilidad, 16(51), 605-613.

Banco de España. (2015). Central de Balances: Resultados anuales de las empresas no financieras 2006-2013, 2014 provisional y avance de resultados de 2015.

http://www.bde.es/f/webbde/SES/Secciones/Publicacio nes/PublicacionesAnuales/CentralBalances/15/Fich/ceb a15.pdf

Burchell, S., Clubb, C., y Hopwood, A. (1985).

Accounting in its social context. Towards a history of value added in the United Kingdom. Accounting,

Organizations and Society, 10(4), 383-413.

https://doi.org/10.1016/0361-3682(85)90002-9

Cahan S. F., y van Staden, D. J. (2009). Black economic empowerment, legitimacy and the value added statement: evidence from post-apartheid South Africa, Accounting and Finance, 49(1), 37-58.

https://doi.org/10.1111/j.1467-629x.2008.00280.x

Carrasco, F. (1999). Fundamentos del sistema europeo de cuentas nacionales y regionales -SEC95. Pirámide.

Comisión Europea. (2011). Comunicación de la Comisión al Parlamento Europeo, al Consejo, al Comité Económico y Social Europeo y al Comité de las Regiones. Estrategia renovada de la UE para 20112014 sobre la responsabilidad social de las empresas. Bruselas, 25.10.2011. COM(2011) 681 final. https://eur-lex.europa.eu/legalcontent/ES/ALL/?uri=celex\%3A52011DC0681

Comisión Nacional del Mercado de Valores. (2021). Líneas estratégicas de la CNMV 2021-2022. Plan de actividades 2021.

https://www.cnmv.es/DocPortal/Publicaciones/PlanAct ividad/Plan_Actividades_2021.PDF
Déniz Mayor, J. J., Arteaga Arzola, L. M., y Manrique de Lara Peñate, $C$.
Vol. 7, núm. 19 / enero - abril del 2022 DOI: https://doi.org/10.36791/tcg.v7i19.135 Pp. 107-149 
Conseil National de la Comptabilité. (1992). Plan General Francés de Contabilidad (Trad. Fernández Peña, E y Mallo Rodríguez, C.). Instituto de Contabilidad y Auditoría de Cuentas. (Texto original publicado en 1982).

Consejo Profesional de Ciencias Económicas de la Ciudad Autónoma de Buenos Aires (CPCECABA). (2013). Resolución Técnica FACPCE 36. Normas Contables Profesionales: Balance Social. https://consejo.org.ar/storage/attachments/RT_FACPC E_N36.pdf-XKV91T7WyA.pdf

Cuarta Directiva 78/660/CEE del Consejo, de 25 de julio de 1978, basada en la letra g) del apartado 3 del artículo 54 del Tratado y relativa a las cuentas anuales de determinadas formas de sociedad. Diario Oficial de las Comunidades Europeas, núm. L 222/11, de 14 de agosto, pp. 55 - 73. https://eur-lex.europa.eu/legalcontent/ES/TXT/PDF/?uri=CELEX:31978L0660\&fro $\mathrm{m}=\mathrm{ES}$

Dierkes, M. (1979). Corporate social reporting in Germany: Conceptual developments and practical experience. Accounting, Organizations and Society, 4(1-2), 87-107. https://doi.org/10.1016/03613682(79)90010-2

Directiva 2014/95/UE del Parlamento Europeo y del Consejo, de 22 de octubre, por la que se modifica la Directiva 2013/34/UE en lo que respecta a la divulgación de información no financiera e información sobre diversidad por parte de determinadas grandes empresas y determinados grupos. Diario Oficial de la Unión Europea, núm. L 132, de 15 de noviembre de 2014, pp. L330/1 - L330/9. https://eur-lex.europa.eu/legalcontent/ES/TXT/?uri=CELEX:32014L0095
Directiva (UE) 2017/828 del Parlamento Europeo y del Consejo, de 17 de mayo, por la que se modifica la Directiva 2007/36/CE en lo que respecta al fomento de la implicación a largo plazo de los accionistas. Diario Oficial de la Unión Europea, núm. L 132, de 20 de mayo de 2017, pp. L132/1 - L132/25. https://eurlex.europa.eu/legalcontent/ES/TXT/?uri=CELEX\%3A32017L0828

ICSA Grupo (2020). Evolución salarial 2007-2019. 13a edición. EADA Business School \& ICSA Grupo. https://www.eada.edu/es/actualidad/noticias/2020/01/1 3o-informe-evolucion-salarial-2007-2019-de-eada-eicsa-grupo

Fernández, D. (03 de mayo de 2015). La brecha salarial se profundiza. El País.

https://elpais.com/economia/2015/05/01/actualidad/143 0488302_647891.html

Fernández, J. (1983). Teoría económica de la contabilidad: Introducción contable al estudio de la economía. Ediciones ICE.

Fleming, P. (2017). The human capital hoax: Work, debt and insecurity in the Era of Uberization. Organization Studies, 38(5), 691-709. https://doi.org/10.1177/0170840616686129

Flores, M. (2005). La determinación de la creación de riqueza empresarial: El Estado de Valor Añadido. Partida Doble, 168, 60-69.

Gallizo, J. (1990). El valor añadido en la información contable de la empresa: Análisis y aplicaciones. Instituto de Contabilidad y Auditoría de Cuentas.

Global Reporting Initiative. (2014). G4 - Guía para la elaboración de memorias de sostenibilidad. https://www.globalreporting.org/resourcelibrary/Spanis h-G4-Part-two.pdf
Déniz Mayor, J. J., Arteaga Arzola, L. M., y Manrique de Lara Peñate, $C$. 
Global Reporting Initiative. (2016). GRI 201:

Desempeño económico 2016.

https://www.globalreporting.org

Gómez, J. (2019). Remuneración e incentivos de los consejeros ejecutivos en las empresas del Ibex 35 entre 2013 y 2017. Boletín de la CNMV, Trimestre I, 123159.

https://www.cnmv.es/DocPortal/Publicaciones/Boletin/ Boletin_I_2019.pdf

Gonzalo, J. A., y Pérez, J. (2017). Una propuesta de normalización relativa al valor añadido como medida alternativa de rendimiento empresarial, Revista AECA, 119, 35-39. https://aeca.es/wpcontent/uploads/2014/05/119.pdf

Gorosito, S., y Curto, L. (1997). El estado de valor agregado. Revista de la Facultad de Ciencias Económicas y Sociales, 9, 153-163. http://eco.mdp.edu.ar/cendocu/repositorio/FACES_n4_ 153-163.pdf

Gracia, A. (06 de agosto de 2013). Automovilismo y minería, los sectores que más subvenciones reciben del Estado. El Confidencial.

http://www.elconfidencial.com/empresas/2013-0806/automovilismo-y-mineria-los-sectores-que-massubvenciones-reciben-del-estado_15655/

Grupo Inditex (2018). Balance de sostenibilidad 2017. https://static.inditex.com/annual_report_2017/balancesostenibilidad.

Haller, A., y van Staden, C. (2014). The value added statement - an appropriate instrument - for Integrated Reporting. Accounting, Auditing \& Accountability Journal, 27(7), 1193-1203.

https://doi.org/10.1108/AAAJ-04-2013-1307
Haller, A., van Staden, C. J., y Landis, C. (2018). Value added as part of sustainability reporting: Reporting on distributional fairness or obfuscation? Journal of Business Ethics, 152, 763-781. https://doi.org/10.1007/s10551-016-3338-9

Hernández, M. (1997). El valor añadido como indicador económico de la responsabilidad social [tesis doctoral, Universidad de La Laguna].

ftp://tesis.bbtk.ull.es/ccssyhum/cs47.pdf

Hernández Estévez, E. (2011). La revolución contable de comienzos del siglo XX. Boletín AECA, 95, 40-45. http://www.aeca1.org/revistaeca/revista95/95.pdf.

Iberdrola. (2019). Estado de información no financiera. Informe de sostenibilidad. Ejercicio 2018. https://www.iberdrola.com/wcorp/gc/prod/es_ES/corpo rativos/docs/IB_Informe_Sostenibilidad.pdf

Instituto de Contabilidad y Auditoría de Cuentas (ICAC). (2002). Informe sobre la situación actual de la contabilidad en España y líneas básicas para abordar su reforma (Libro Blanco para la reforma de la contabilidad en España). ICAC.

https://inza.files.wordpress.com/2013/09/icac-libroblanco-contabilidad.pdf

Instituto Nacional de Estadística (INE). (2012). Clasificación Nacional de Actividades Económicas CNAE-2009. Notas explicativas. Actualizado el $17 / 02 / 2012$.

http://www.ine.es/daco/daco42/clasificaciones/cnae09/ notasex_cnae_09.pdf

International Accounting Standard Board (IASB). (2006). Norma Internacional de Contabilidad $n^{\circ} 1$ Presentación de estados financieros. http://www.normasinternacionalesdecontabilidad.es/NI C/pdf/NIC01.pdf
Déniz Mayor, J. J., Arteaga Arzola, L. M., y Manrique de Lara Peñate, C. 
Larrinaga, C. (2001). Aspectos sociales y políticos del estado de valor añadido. Revista de Contabilidad, 4(8), 35-62.

Loi n ${ }^{\circ}$ 73-4 du 2 janvier 1973 relative au code du travail. Journal Officiel de la République Française, núm.105(2), du 3 janvier 1973, pp.52-135. https://www.legifrance.gouv.fr/download/securePrint?t oken=bmeqeh3Kp@iqQ0\$xeW5s

Loi $n^{\circ}$ 77-769 du 12 juillet 1977 relative au bilan social de l'entreprise. Journal Officiel de la République Française, núm109(161), du 13 juillet 1977, pp.3699 3670.

https://www.legifrance.gouv.fr/jorf/id/JORFTEXT000 000322331

Maji, S. K. (2016). The State of value added statement in India: An empirical inquest. Journal of Accounting Research \&Auditing Practices, 15(2), 7-22.

Morley, M. F. (1979). The value added statement in Britain. The Accounting Review, 54(3), 618-629. https://www.jstor.org/stable/245988.

Nerinckx, S. (2016). The 'Uberization' of the labour market: some thoughts from an employment law perspective on the collaborative economy. ERA Forum, 17, 245-265. https://doi.org/10.1007/s12027-016-0439$\mathrm{y}$

Nicklisch, H. (1920). Der Weg aufwärts!: Organisation; Versuch einer Grundlegung. Proeschel.

Pastor, S., Ribas, F., y Santiago, O. (2011). El estado de valor agregado. XXXII Jornadas Universitarias de Contabilidad. Rosario, Argentina. http://www.uca.edu.ar/uca/common/grupo6/files/juc9.pdf
Perera, L. (2014). “Democratizando la información contable. Estados de valor agregado y la huella de valor”. Cuadernos de RSO, 2(1), 36-52.

https://ucu.edu.uy/sites/default/files/facultad/fce/rso/RS O_vol2_Perera.pdf

Pong, C., y Mitchell, F. (2005). Accounting for a disappearance: A contribution to the history of the value added statement in the UK. The Accounting Historians Journal, 32(2), 173-199. http://www.jstor.org/stable/40698573, https://doi.org/10.2308/0148-4184.32.2.173

Real Decreto 1643/1990, de 20 de diciembre, por el que se aprueba el Plan General de Contabilidad, Boletín Oficial del Estado, núm. 310, de 27 de diciembre de 1990, pp.38531 - 38616.

https://www.boe.es/eli/es/rd/1990/12/20/1643

Real Decreto 1514/2007, de 16 de noviembre, por el que se aprueba el Plan General de Contabilidad. Boletín Oficial del Estado, núm. 278, de 20 de noviembre. https://www.boe.es/eli/es/rd/2007/11/16/1514/con

Reglamento (UE) 549/2013 del Parlamento Europeo y del Consejo, de 21 de mayo de 2013, relativo al Sistema Europeo de Cuentas Nacionales y Regionales de la Unión Europea [SEC2010]. Diario Oficial de la Unión Europea, núm. L174, de 26 de junio de 2013, pp. L174/1 - L174/27. https://eur-lex.europa.eu/legalcontent/ES/ALL/?uri=celex:32013R0549

Reichmann, T., y Lange, C. (1980). Kapitalflußrechnung und Wertschöpfungsrechnung als Ergänzungsrechnungen des Jahresabschlusses im Rahmen einer gesellschaftsbezogenen Rechnungslegung. Zeitschrift für Betriebswirtschaft, 50 (5), 518-542. 
Reichmann, T., y Lange, C. (1981). The value added statement as part of corporate social reporting. Management International Review, 21(4), 17-22. https://www.jstor.org/stable/40227610

Repsol. (2016). Informe de sostenibilidad 2015. http://memorias.repsol.com/media/pdf/informesostenibilidad/es/completo/Informe_Sostenibilidad.pdf

Riahi-Belkaoui, A., y Picur. R. D. (1994). Net value added as an explanatory variable for returns. Managerial Finance, 20(9), 56-64. https://doi.org/10.1108/eb018492

Riahi-Belkaoui, A., y Picur, R. D. (1999). The substitution of net value added for earnings in equity valuation. Managerial Finance, 25(12), 66-78. https://doi.org/10.1108/03074359910766352

SABI. (2019). Base de datos. http://www.einforma.com/sabi

Stainbank, L. J. (2009). The value added statement: does it add any value? Meditari Accountancy Research, 17(2), 137-149.

https://doi.org/10.1108/10222529200900016

StataCorp. (2009). Stata Statistical Software: Release 11 [software]. College Station, StataCorp LP. http://www.stata.com

Telefónica. (1985). Memoria anual. Compañía Telefónica Nacional de España. https://www.telefonica.com/documents/153952/133478 43/1985.pdf
Van Staden, C. (2003). The relevance of theories of political economy to the understanding of financial reporting in South Africa: the case of value added statements. Accounting Forum, 27(2), 224-245. https://doi.org/10.1111/1467-6303.00103

Van Staden C. J. y Vorster, Q. (1998). The usefulness of the value added statement: a review of the literature. Meditari Accountancy Research, 6, 337-351. https://repository.up.ac.za/handle/2263/15601

Vélez, A. M. (08 de mayo de 2019). Los sueldos de los ejecutivos del Ibex van por libre: la cotización de las empresas tiene un impacto irrelevante. elDiario.es. https://www.eldiario.es/economia/ejecutivos-ibexcotizacion-empresas-irrelevante_1_1559657.html

Veras Machado, M., da Silva Macedo, M. A., y Reis Machado, M. (2014). Analysis of the relevance of information content of the value added statement in the Brazilian capital markets. Revista Contabilidade \& Finanças, 26(67), 57-69. https://doi.org/10.1590/1808057x201512240

Volkswagen Group. (2018). Value added statement. Annual report 2017. https://annualreport2017.volkswagenag.com/groupmanagement-report/value-added-statement.html
Déniz Mayor, J. J., Arteaga Arzola, L. M., y Manrique de Lara Peñate, C.
Vol. 7, núm. 19 / enero - abril del 2022 DOI: https://doi.org/10.36791/tcg.v7i19.135 Pp. 107-149 